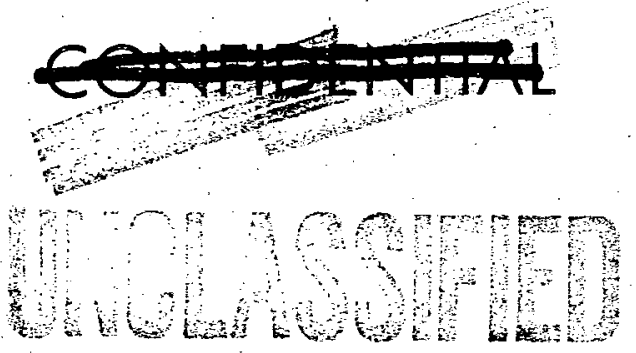

BNL 885

(-91. Nuclear Reactors for Rocket Propulsion

M-3679 (37th Ed.)

BNL Log No. R-26272

\title{
FLUIDIZED BED REPROCESSING OF ROVER FUEL
}

\author{
J.J. REILLY, S.J. WACHTEL, R. JOHNSON, \\ E. WIRSING, JR., AND L.P. HATCH
}
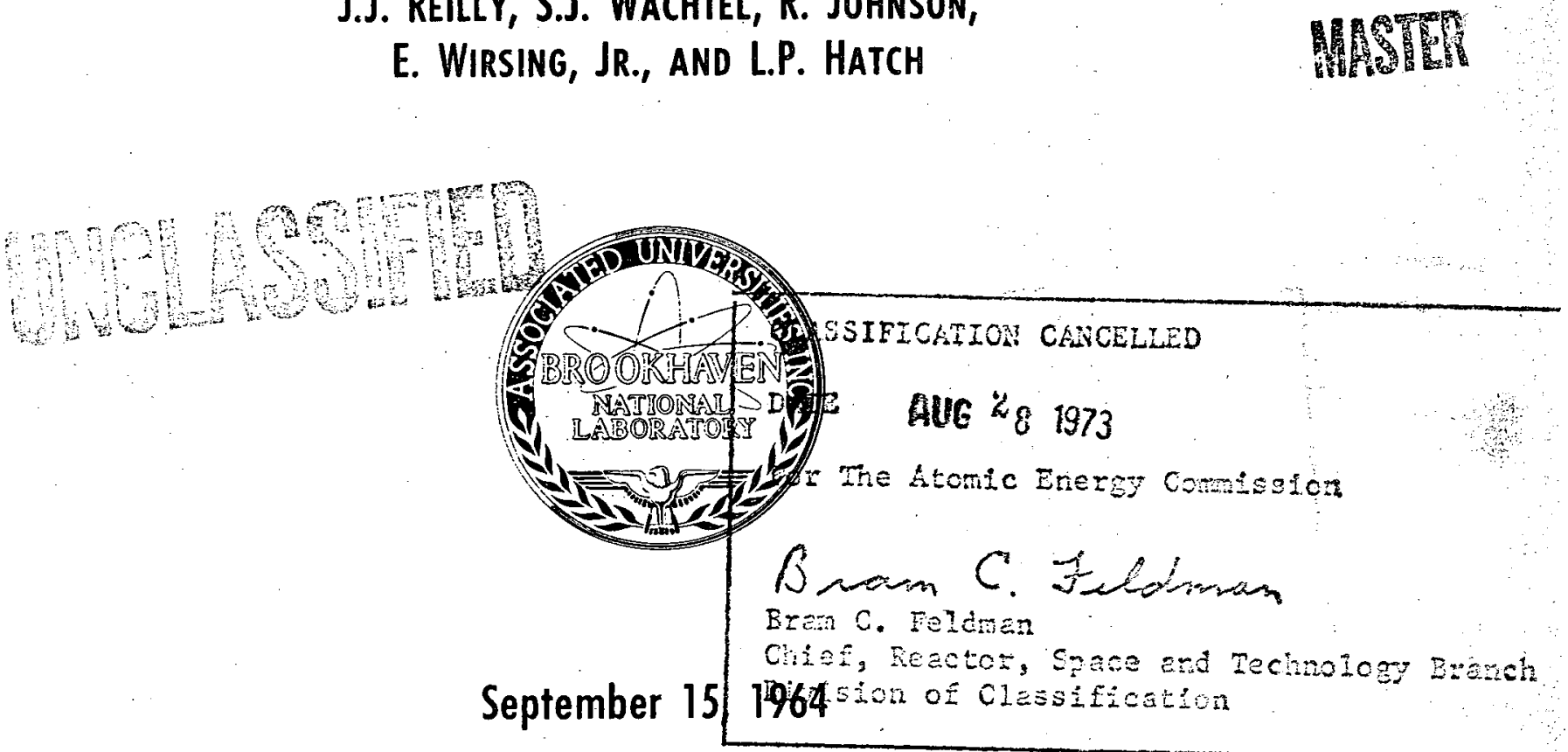

\section{AEC RESEARCH AND DEVELOPMENT REPORT}

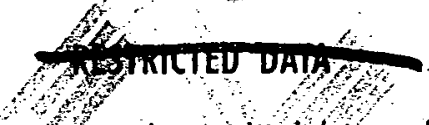

This documenf contains restricted data as defined in the Atamic Energy Act of 1954. Its transmittal or the disclosure of its contents in any manner ifo an unauthorized person is prohibited.
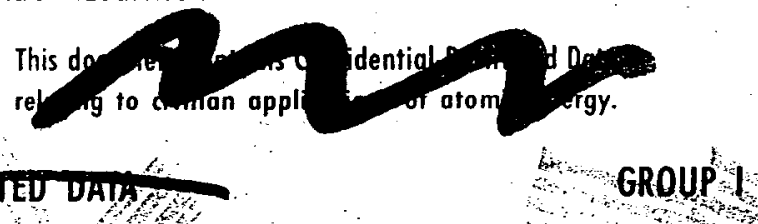

Excluded from automáticyowntoming and declassification.

\section{BROOKHAVEN NATIONAL LABORATORY}

ASSOCIATED UNIVERSITIES, INC.

under contract with the

UNITED STATES ATOMIC ENERGY COMMISSION

$3 \quad 340$ 


\section{DISCLAIMER}

This report was prepared as an account of work sponsored by an agency of the United States Government. Neither the United States Government nor any agency Thereof, nor any of their employees, makes any warranty, express or implied, or assumes any legal liability or responsibility for the accuracy, completeness, or usefulness of any information, apparatus, product, or process disclosed, or represents that its use would not infringe privately owned rights. Reference herein to any specific commercial product, process, or service by trade name, trademark, manufacturer, or otherwise does not necessarily constitute or imply its endorsement, recommendation, or favoring by the United States Government or any agency thereof. The views and opinions of authors expressed herein do not necessarily state or reflect those of the United States Government or any agency thereof. 


\section{DISCLAIMER}

Portions of this document may be illegible in electronic image products. Images are produced from the best available original document. 


\title{
FLUIDIZED BED REPROCESSING OF ROVER FUEL
}

\author{
J.J. REILLY, S.J. WACHTEL, R. JOHNSON, \\ E. WIRSING, JR., AND L.P. HATCH
}

\begin{tabular}{|c|c|c|c|}
\hline $\begin{array}{l}\text { SPBCLAL REREVIEW } \\
\text { FINAL } \\
\text { DETERMINATON } \\
\text { Goss: }-\lfloor\end{array}$ & $\begin{array}{l}\text { Reviewers } \\
D B Q U \\
R P\end{array}$ & $\begin{array}{l}\text { Class. } \\
L\end{array}$ & $\frac{0.3 / 10 / 82}{0.3 / 66 / 82}$ \\
\hline
\end{tabular}

September 15, 1964
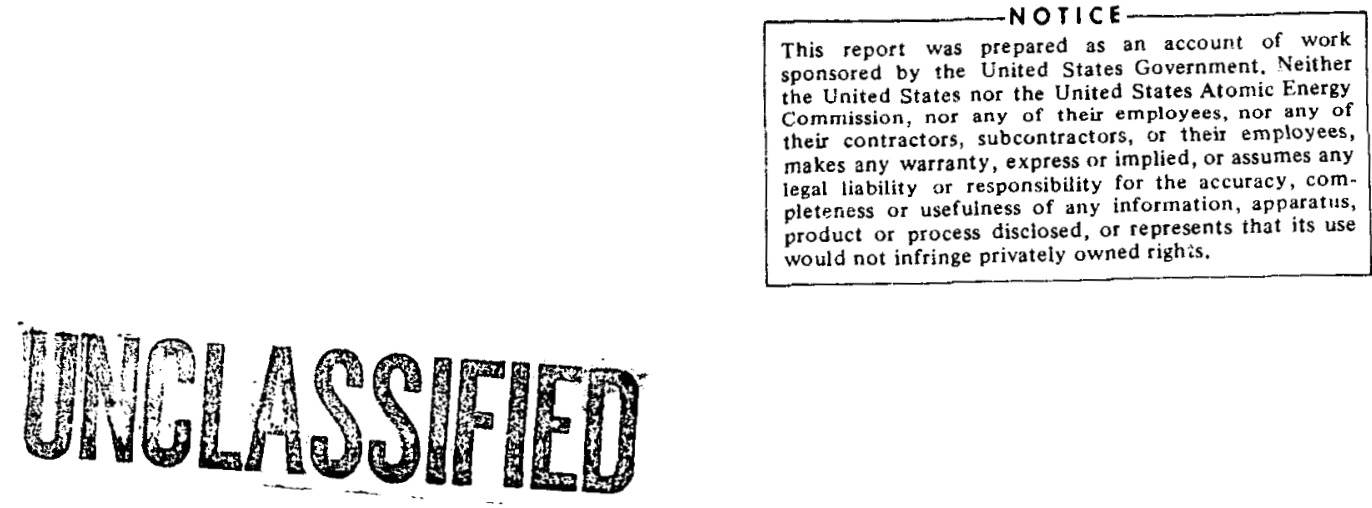

would not infringe privately owned righis.

BROOKHAVEN NATIONAL LABORATORY UPTON, NEW YORK

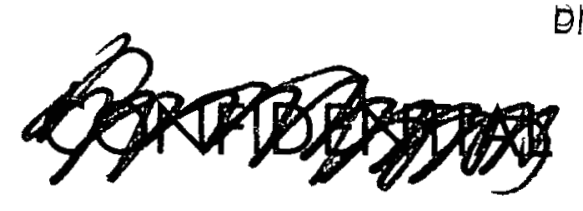

EISTRIRUTION OF THIS DOCUMENT IS UNLIMITED 


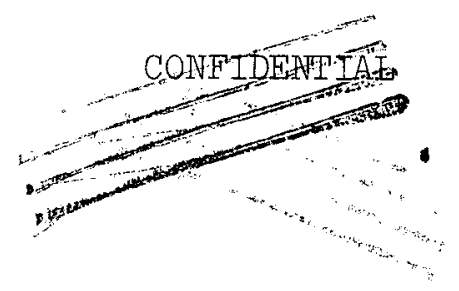

$\ominus$

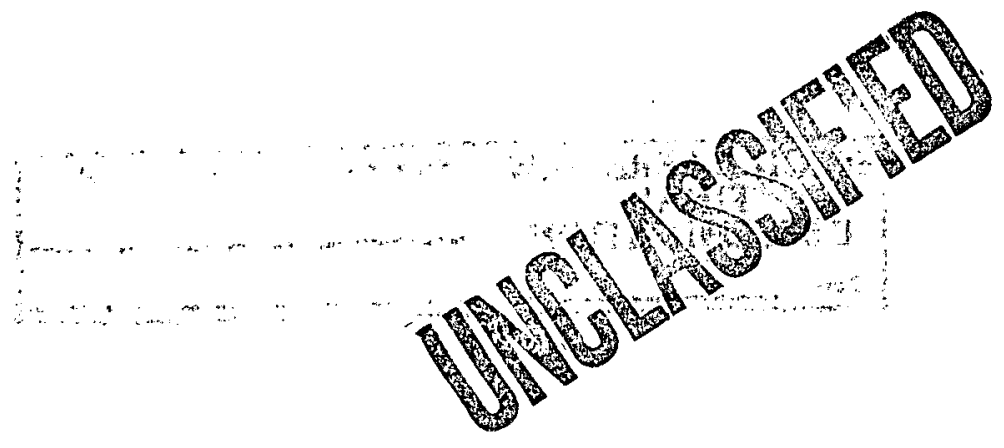

Printed in U.S.A. Charge \$.90. Available from the U.S. Atomic Energy Commission, Division of Technical Information Extension, P.0. Box 1001, Oak Ridge, Tennessee. Please direct to the same address inquiries covering the procurement of other classified AEC reports.

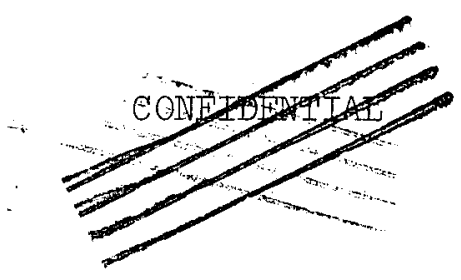



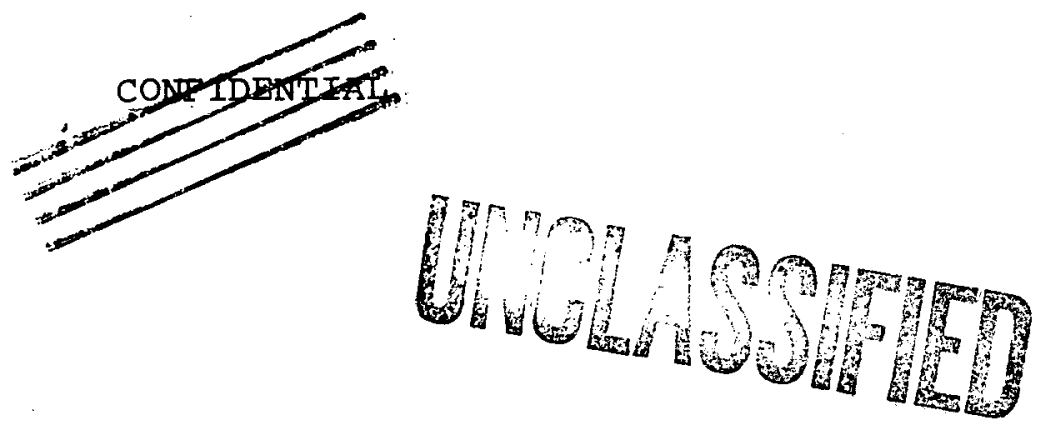

ABSTRACT

A fluidized bed volatility pilot plant designed to demonstrate the reprocessing of Rover fuel has been operated with satisfactory results. Unirradiated chopped Rover fuel was reacted continuously with oxygen at $750^{\circ} \mathrm{C}$ within a fluidized bed of alundum. Carbon was removed as $\mathrm{CO}_{2}$ while $\mathrm{UC}_{2}$ and $\mathrm{NbC}$ were converted to their respective oxides. After oxidation the bed material was transferred to a fluidized bed fluorinator in which volatile $\mathrm{UF}_{6}$ and $\mathrm{NbF}_{5}$ were produced by reaction with fluorine at $450^{\circ} \mathrm{C}$. Separation of $\mathrm{UF}_{6}$ from $\mathrm{NbF}_{5}$ was effected via partial condensation and selective absorption on NaF.

An aqueous alternate to the fluorination step was investigated in which the oxidized bed was leached with nitric acid to dissolve $\mathrm{U}_{3} \mathrm{O}_{8}{ }^{\circ}$ However, a further leaching step with a hydrofluoric-nitric acid mixture was required to obtain satisfactory (>99\%) uranium recovery.

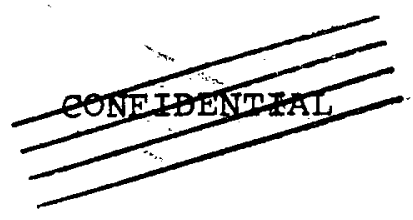




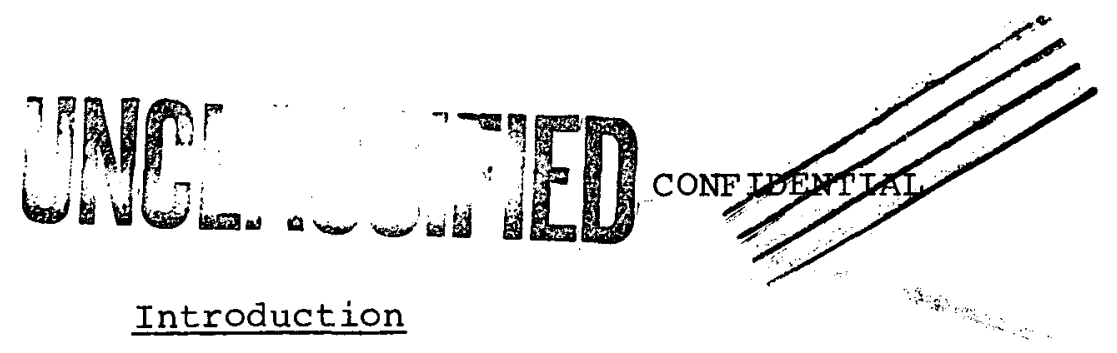

Effective control of temperature in highly exothermic reactions between gases and massive solids may be readily accomplished when such reactions are carried out in fluidized beds of inert granular materials. ${ }^{1}$ In this method the solid reactant is immersed in a fluidized bed of inert particles, such as alumina, in which the fluidizing gas is, or contains, the gaseous reactant. The inert bed material serves to transport the heat of reaction to the wall of the reactor, which is externally cooled, and does not give rise to corrosion and other containment problems commonly associated with reaction systems involving liquid heat transfer media such as interhalogens and fused salts.

During the past six years a continuing program has been carried out at Brookhaven National Laboratory on the development of fluidized bed systems for reprocessing nuclear reactor fuels by means of volatile separations. This report will cover the results obtained in a fluidized bed volatility pilot plant designed specifically to recover uranium from Rover fuel.

The Rover fuel elements used in the pilot plant experiments were not irradiated and contained depleted instead of enriched uranium. The elements were of the Kiwi $B$ type which are in the form of graphite rods, 0.75 inches in diameter and up to 52 inches long, having either 7 or 19 longitudinal coolant passages lined with NoC. In some fuel elements of this type the $U$ is homogeneously dispersed throughout the graphite matrix. In other elements of recent design, the $U$ is dispersed throughout the matrix in the form of pyrolytic carbon-coated particles of $\mathrm{UC}_{2} \cdot$ Both types of fuel have been used in this investigation and no essential difference has been found in their behavior. Although the fuel used in this study did not

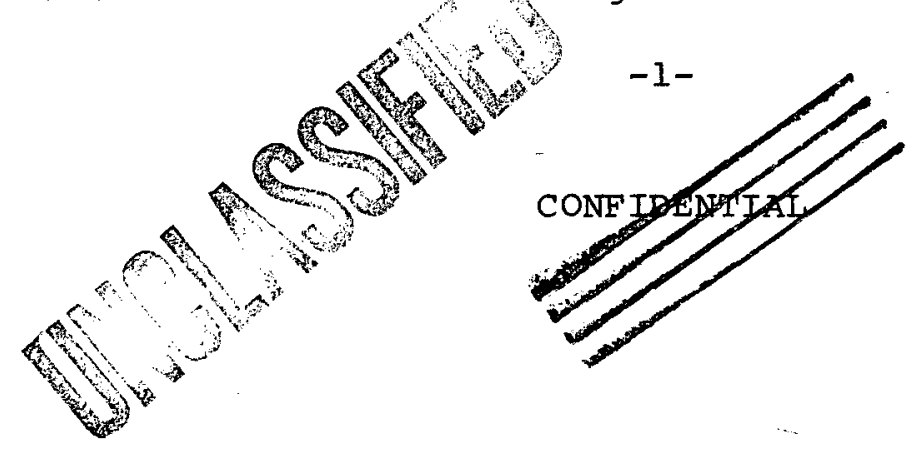


have any significant amount of $U$ in the NbC liner material, in both fuel types as much as $5 \%$ of the total $U$ may migrate to the $\mathrm{NbC}$ liner material during manufacture and reactor testing.

Two processes for the recovery of $U$ from Rover fuel have been studied, each using the inert fluidized bed technique. A block diagram of the process steps is shown in Fig. 1. In each process carbon is burned in a head end fluid bed oxidation step and the non-volatile fuel constituents are converted to oxides. The major reactions taking place in this step are:

$$
\begin{aligned}
\mathrm{C} & +\mathrm{O}_{2} \stackrel{750^{\circ} \mathrm{C}}{\rightarrow} \mathrm{CO}_{2} \\
\mathrm{C} & +\frac{1}{2} \mathrm{O} \\
3 \mathrm{UC}_{2} & +10 \mathrm{O}_{2} \rightarrow \mathrm{U}_{3} \mathrm{O}_{8}+6 \mathrm{CO}_{2} \\
2 \mathrm{NbC} & +4 \frac{1}{2} \mathrm{O}_{2} \rightarrow \mathrm{Nb}_{2} \mathrm{O}_{5}+2 \mathrm{CO}_{2}
\end{aligned}
$$

Following oxidation, $U$ can be recovered by either a volatility or an aqueous route. In the volatility (burn-fluorination) process, the bed containing the finely divided oxidation products $\left(\mathrm{U}_{3} \mathrm{O}_{8}\right.$ and $\left.\mathrm{Nb}_{2} \mathrm{O}_{5}\right)$ is fluorinated and $\mathrm{U}$ recovered as the volatile hexafluoride. The $\mathrm{No}_{2} \mathrm{O}_{5}$ product is converted to the volatile pentafluoride. The major reactions in this step are:

$$
\begin{aligned}
& \mathrm{U}_{3} \mathrm{O}_{8}+9 \mathrm{~F}_{2} \stackrel{450^{\circ} \mathrm{C}}{\rightarrow} 3 \mathrm{UF}_{6}+4 \mathrm{O}_{2} \\
& \mathrm{Nb}_{2} \mathrm{O}_{5}+5 \mathrm{~F}_{2} \rightarrow 2 \mathrm{NbF}_{5}+2 \frac{1}{2} \mathrm{O}_{2}
\end{aligned}
$$

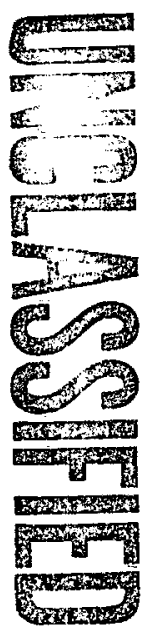

$\mathrm{NbF}_{5}$ is separated from the $\mathrm{UF}_{6}$ product by selective condensation and absorption.

In the alternate aqueous (burn-leach) process the oxidized bed is leached with nitric acid which dissolves the bulk of the

$$
-2-
$$

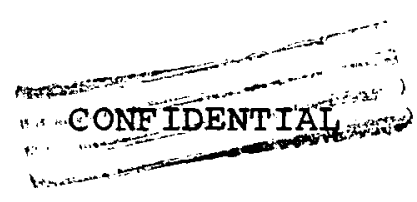




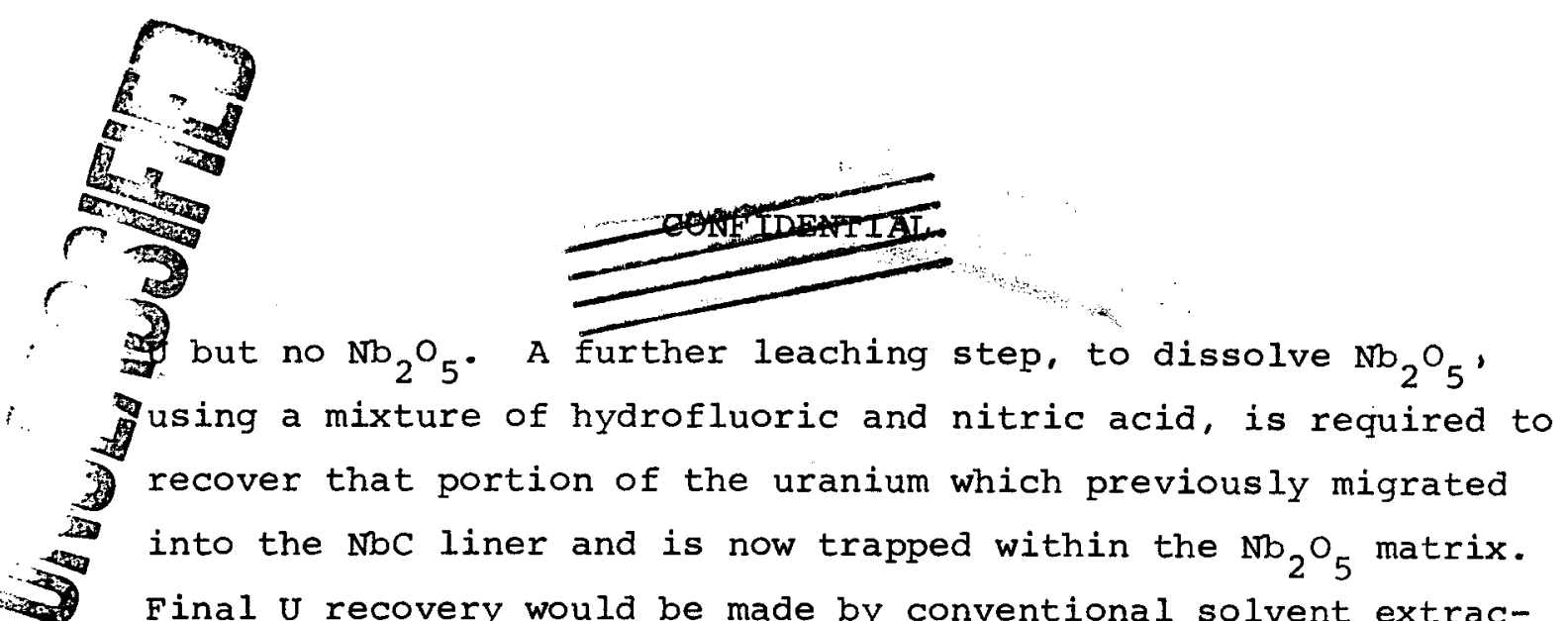
Final U recovery would be made by conventional solvent extraction techniques.

\section{Pilot Plant Description}

A diagram of the fluidized bed volatility pilot plant is shown in Fig. 2. The Nickel 201 oxidizer has a reaction (fluidized bed) section 8.3 feet long by 4 inches $i . d .$, which is topped by an 8-inch diameter disengaging section 3 feet long. A 6-inch diameter internally finned, water-cooled section above the disengaging plenum serves as an off-gas cooler and filter housing for two stainless steel porous metal filters. The filters, attached to the top flange of the housing, are 18 inches long $\times 2-3 / 4$ inches in diameter with a mean pore size of 20 microns and are provided with a pulsed $\mathrm{N}_{2}$ blowback system. A fuel-charging chute, which consists of a short length of 2-inch diameter pipe, is set into the filter housing at an angle of $45^{\circ}$ approximately 9 inches above the bottom of the filter housing. The chute extends outward approximately 8 inches and terminates in a charging lock made up with two ball valves.

Preheated feed gas enters the reactor through a conical bottom equipped with a ball check. Bed material is discharged near the bottom of the reactor by fluidizing a sealpot located in a 4-inch i.d. bed receiver vessel. The fuel charge is supported by a grate approximately 27 inches above the gas inlet.

The outer wall of the 4 -inch diameter reaction section is finned and surrounded by an 8-inch diameter, 7-foot long Inconel shell. A diagram of the oxidizer is shown in Fig. 3.

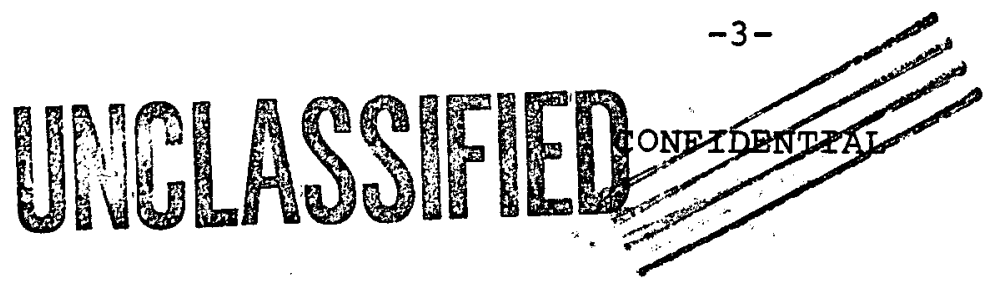




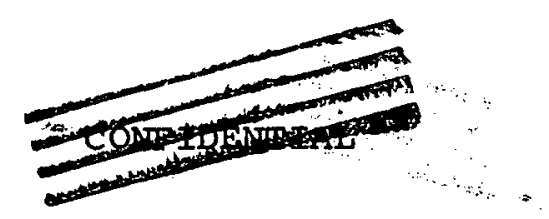

Chromolax heaters placed between the fins supply a maximum of $11 \mathrm{kw}$ of heat to the reactor. The finned annulus formed by the reactor and shell serves as a plenum for cooling air which is circulated by a blower.

Bed material is transferred pneumatically from the bed receiver to the fluorinator (or leach column) through one-half inch tubing. Recycled bed or fresh alundum is charged to the oxidizer from a feed hopper mounted above the reactor by fluidizing a sealpot located just beneath the hopper outlet line which extends 2 inches into the oxidizer disengaging space.

Both the reactor wall and bed centerline temperatures were measured at several locations and recorded either on multipen or multipoint print-out recorders. A portion of the off-gas stream was analyzed for carbon monoxide and carbon dioxide continuously by infrared analyzers and periodically via a gas chromatograph. The differential pressure across both the bed and the filters was continuously recorded.

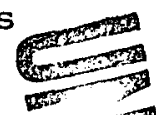

A diagram of the 4-inch diameter fluorinator is shown in Fig. 5. The fluorinator is 12.3 feet long and constructed of Nickel 201. It has no disengaging section. The lower section is surrounded by an Inconel metal shell 8. inches i.d. by 7 feet long. The shell forms an annular path through which cooling air is circulated, however, the fluorinator is not finned. Attached to the top flange are two 18 -inch $\times 1 \frac{1}{2}$-inch diameter Monel porous metal filters which are provided with a pulsed inert gas blowback system. Feed gas is introduced into the fluorinator through a conical bottom fitted with a ball check. Bed material is discharged through a 3/4-inch outlet line located in the conical bottom. The reactor is fitted with thermocouples

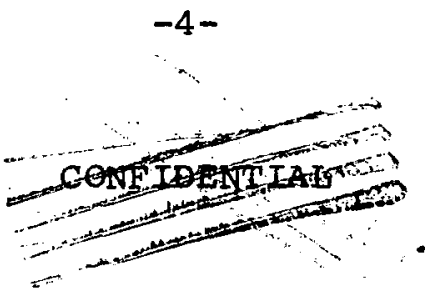



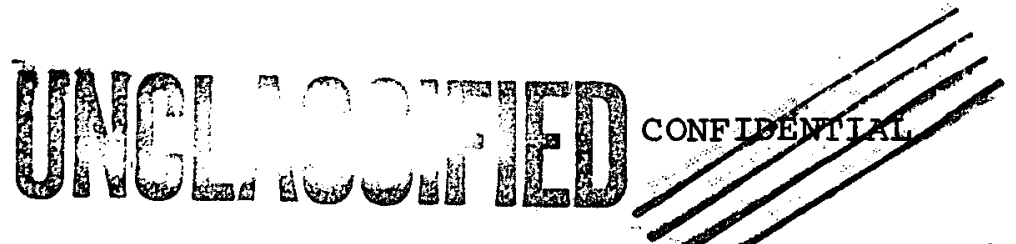

and pressure taps in a ner of locations. Off-gases from the fluorinator are conducted through 3/4-inch tubing to a $\mathrm{UF}_{6}$ recovery and purification system. This system, designed and built at Oak Ridge Gaseous Diffusion Plant (ORGDP), consists of four units: a condenser in which the major portion of the $\mathrm{NbF}_{5}$ is separated from the UF ${ }_{6}$ stream by partial condensation, a high temperature NaF column which serves as an $\mathrm{NbF}_{5}$ cleanup trap, a $\mathrm{UF}_{6}$ cold trap and a final NaF column for removal of trace amounts of $\mathrm{UF}_{6}$ which are not desublimed in the preceding cold trap.

The $\mathrm{NbF}_{5}$ condenser, 5 inches in diameter by 5 feet 1ong, is internally finned and air heated and cooled. The UF ${ }_{6}$ trap is of similar dimensions and is also internally finned. It is cooled by a recirculating refrigerant and is provided with cal rod heating elements. Both NaF columns are constructed of 5-inch pipe ( 5 feet long) flanged at both ends and are provided with cal rod heating elements. A detailed description of the recovery system and its performance is given elsewhere ${ }^{2}$. After passing through the recovery system, the off-gases are conducted to a caustic scrubber in which excess fluorine is removed from the off-gas stream through reaction with $10 \% \mathrm{KOH}$ solution. The scrubber effluent (inert gas and $\mathrm{O}_{2}$ ) is vented to the atmosphere through a stack.

The pilot plant leaching system is quite simple, its purpose being only to demonstrate the feasibility of the alternate aqueous process. The nitric acid leach column shown in Fig. 6 is a 4-inch diameter glass pipe 48 inches in length. The bottom of the column is fitted with a porous metal disc which serves as a bed support. The leach liquor is circulated through the

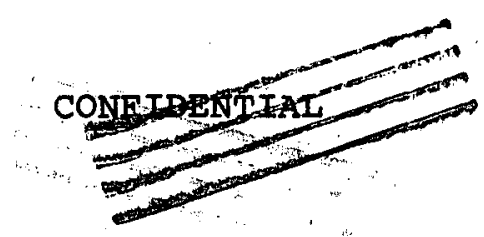




\section{CONEIDENTTAI}
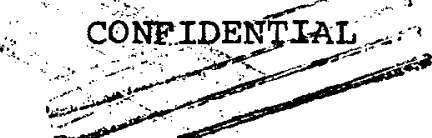

column by a Vanton pum a 10-gallon stainless steel surge tank. The column is provided with a bed transfer line, liquid inlet and outlet line, a porous metal off-gas filter used in the drying and bed transfer steps, and gas inlets at the top and bottom.

\section{Operating Procedure}

\section{A. Oxidation}

In the initial run of any series the reactor was filled to a depth of approximately 5 feet with $20 \mathrm{~kg}$ of alumina (equal weight mixture of 60,90 and 120 mesh nominal particle size alundum Norton grade RRL Approximately $4 \mathrm{~kg}$ of Rover fuel (5-6 rods) in the form of 3/4-inch $x 3 / 4$-inch pieces were added to the oxidizer through the charging lock. In continuous operation, the bed feed hopper was filled with approximately $10 \mathrm{~kg}$ of alumina which was added to the reactor to maintain bed inventory during the run. After charging, the bed was fluidized with $\mathrm{N}_{2}$ and heated to a temperature of $625^{\circ}-650^{\circ} \mathrm{C}$. At this point the $\mathrm{N}_{2}$ was replaced with $100 \% \mathrm{O}_{2}$ as the fluidizing gas feed. After introduction of $\mathrm{O}_{2}$ the bed centerline temperature increased to approximately $750^{\circ} \mathrm{C}$ and cooling air was circulated to hold wall temperatures to a maximum of $710^{\circ} \mathrm{C}$. In continuous operation chopped Rover fuel was added as needed to keep the $\mathrm{O}_{2}$ utilization (or burning rate) high. In practice it was found that further fuel addition was necessary when the unburned fuel in the reactor decreased to approximately three elements $(\sim 2100 \mathrm{~g})$. Usually two or three chopped elements were charged to the reactor every hour without interruption to the oxidation.

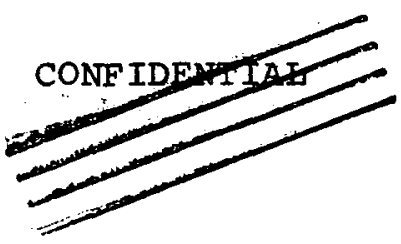


Bed material was withdrawn from the bottom of the oxidizer into the bed receiver continuously or periodically. When the desired amount of bed material was collected in the receiver, it was pneumatically transferred to the fluorinator or leaching column for further treatment.

At the end of an oxidation run the oxygen was replaced with $\mathrm{N}_{2}$ and the reactor was cooled. If the run were part of a series of continuous runs, combustion was terminated while there remained an inventory of $\sim 3$ chopped rods of unburned fuel in the reactor. At the end of any run series the fuel inventory was reacted to completion and the bed drained.

\section{B. Eluorination}

Discharged bed from the oxidizer was transferred to the fluorinator where it was fluidized with $\mathrm{N}_{2}$ and heated to approximately $450^{\circ} \mathrm{C}$. The upper section of the fluorinator was held at approximately $200^{\circ} \mathrm{C}$ in order to keep the filters as cool as possible yet prevent $\mathrm{NbF}_{5}$ condensation. The $\mathrm{NbF}_{5}$ trap was heated to approximately $25^{\circ} \mathrm{C}$ and the high temperature NaF column to $400^{\circ} \mathrm{C}$. The UF 6 cold trap was cooled to $-55^{\circ} \mathrm{C}$ while the final NaF column was heated to $100^{\circ} \mathrm{C}$. All appropriate Iines were heated to prevent condensation of $\mathrm{UF}_{6}$ and $\mathrm{NbF}_{5}{ }^{\circ}$ When operating temperatures were reached, the inlet feed gas composition was adjusted to give a mixture of $25 \% \mathrm{~F}_{2}$ in $\mathrm{N}_{2}$ : In later runs $\mathrm{F}_{2}$ in the feed gas was increased to $50 \%$ during the course of the reaction. After fluorination, the system was purged and the product recovery system evacuated. The NbF 5 condenser and UF 6 trap were isolated by appropriate valving and heated to $100^{\circ} \mathrm{C}$ and $65^{\circ} \mathrm{C}$, respectively, and their contents drained into product cylinders. Samples of each product were taken during the draining operation after which the cylinders were weighed.

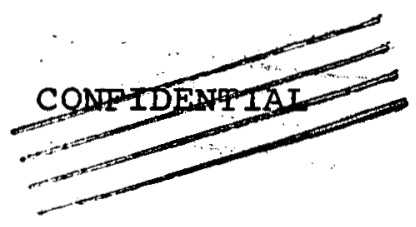




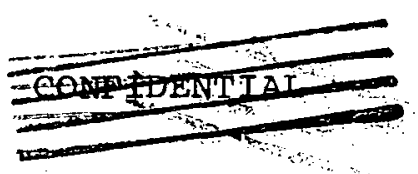

After cooling, the bed material was drained from the fluorinator, sampled and transferred to the oxidizer feed hopper for recycle or discharged to waste.

C. Leaching

In leaching experiments usually $3-5 \mathrm{~kg}$ of bed material was transferred from the bed holdup vessel to the leaching column and contacted with a downflow of about two bed volumes of $6 \mathrm{M} \mathrm{HNO}_{3}$. Usually two leaching passes were carried out. The bed was then washed with two bed volumes of water, dried in place by heat and air flow, sampled, and finally recycled to the oxidizer feed hoppper.

\section{Results}

The results given below are divided into four sections: head end oxidation, $U$ recovery by acid leaching, $U$ recovery by fluid bed fluorination, and corrosion.

\section{A. Oxidation}

A total of 14 pilot plant oxidation runs have been made using Rover fuel. In the first 9 runs (RI to R9) the oxidation served as the head end step for the aqueous recovery scheme (leaching). In Runs R10 through RI4 oxidation was followed by the fluorination step.

The initial two pilot plant oxidation runs were carried out as batch operations in which five chopped Rover fuel rods $(\sim 3700 \mathrm{~g})$ were burned. In Fig. 7 the off-gas composition from Run R2 is plotted vs reaction time. Typical of batch operation, high burning rates were obtained only during the initial reaction period and quite a long tail-off period was necessary to completely oxidize the fuel. 
All subsequent oxidations were carried out on a continuous basis. It is possible to operate continuously with a single reactor and still have a low carbon concentration in the discharged bed since the carbon fines tend to be elutriated and concentrate in the upper portion of the fluidized bed. Thus, while the $\mathrm{C}$ in the discharge bed may be <0.3 wt. \%, the upper portion of the fluidized bed reactor can be as much as 3.0 wt.\%.

The advantages of continuous oxidation are illustrated in Fig. 8 which plots $\mathrm{O}_{2}$ utilization, off-gas composition and fuel burning rate (as $\mathrm{KgC} / \mathrm{hr}$ ) vs cumulative oxidation time for five continuous oxidation runs. No difficulty was encountered in either startup or shutdown procedure in any run, and a high burning rate was established soon after startup. Except during the latter part of Run R7 where the reactor was deliberately run cooler $\left(625^{\circ}-690^{\circ} \mathrm{C}\right.$ bed temperature), the normal bed temperature range was $700^{\circ}-750^{\circ} \mathrm{C}$ with wall temperatures of $650^{\circ}-715^{\circ} \mathrm{C}$. During this run series burning rates averaged $\sim 1.2 \mathrm{~kg}$ of carbon/hr with an $\mathrm{O}_{2}$ utilization of $\sim 90 \%$.

Run R8, a single ten-hour continuous oxidation, was made to investigate the effects of relatively long-term operation on the system and, especially, to determine the effect of increasing the $U$ and $\mathrm{Nb}$ oxide bed concentrations on the burning operation. It is estimated that the $\mathrm{U}$ (as $\mathrm{U}_{3} \mathrm{O}_{8}$ ) content in the bed was increased in the course of the run from $\sim 7.5 \%$ to $\sim 14 \%$ and the $\mathrm{Nb}$ concentration (as $\mathrm{Nb}_{2} \mathrm{O}_{5}$ ) from $\sim 9.5 \%$ to $13.5 \%$. A high burning rate and good oxygen utilization were maintained throughout the first eight hours of burning. After the ninth addition of fuel, a rapid rise in bed centerline temperature directly above the fuel support grid from $\sim 730^{\circ}$ to $870^{\circ} \mathrm{C}$ occurred and was immediately controlled by cutting off the

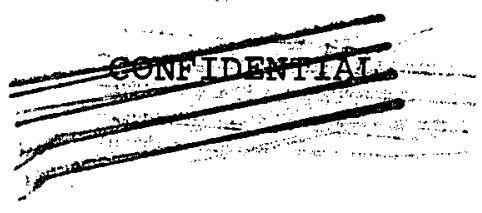




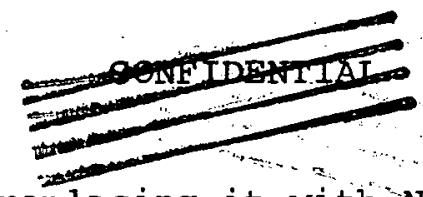

oxygen supply and replacing it with $\mathrm{N}_{2}$ At the same time fluidization quality deteriorated as evidenced by a decrease in the pressure drop across the bed which indicated that bed channeling was occurring. At this point $\sim 3 \mathrm{~kg}$ of 60 -mesh alumina was added to the bed, which restored the bed pressure drop to normal. Upon restoration of good fluidization quality, $100 \% \mathrm{O}_{2}$ was reintroduced and the run was continued for an additional two hours with no further incident.

The particle size distribution of a portion of bed withdrawn during the course of Run R8 before the temperature excursion occurred is shown in Fig. 9. Also shown in the figure are particle size analyses of previous bed samples. The buildup of fines during the course of the experimental series is clearly shown. Fresh RR alundum as charged (equal weight of $60,90,120$ mesh) has $2 \%<140$ mesh whereas the R8 bed had $31 \%$ $<140$ mesh before leaching.

The temperature excursion in Run R8 may be almost certainly traced to the large amount of fines which were present in the bed because of its high $\mathrm{U}_{3} \mathrm{O}_{8}$ and $\mathrm{Nb}_{2} \mathrm{O}_{5}$ content and some attrition of the alundum. The restoration of good fluidization quality upon the addition of the 60-mesh alumina supports this view.

A further burning run, R9, in which no fuel was added, was performed later to complete the oxidation of the fuel already in the burner. This run terminated the burn-leach run series.

At the conclusion of $\mathrm{R} 9$ the entire bed was drained and the head of the filter housing was removed and the filters inspected. They were coated with a very light carbonaceous film as were the vertical surfaces of the wall and cooling fins. Horizontal surfaces were more heavily covered. Examination of the reactor showed it to be clear of any bed or fuel material except for a small amount of bed material at the bottom of the reactor between

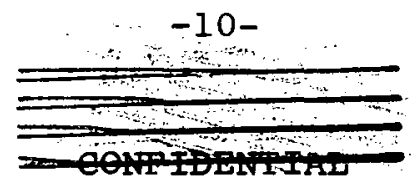



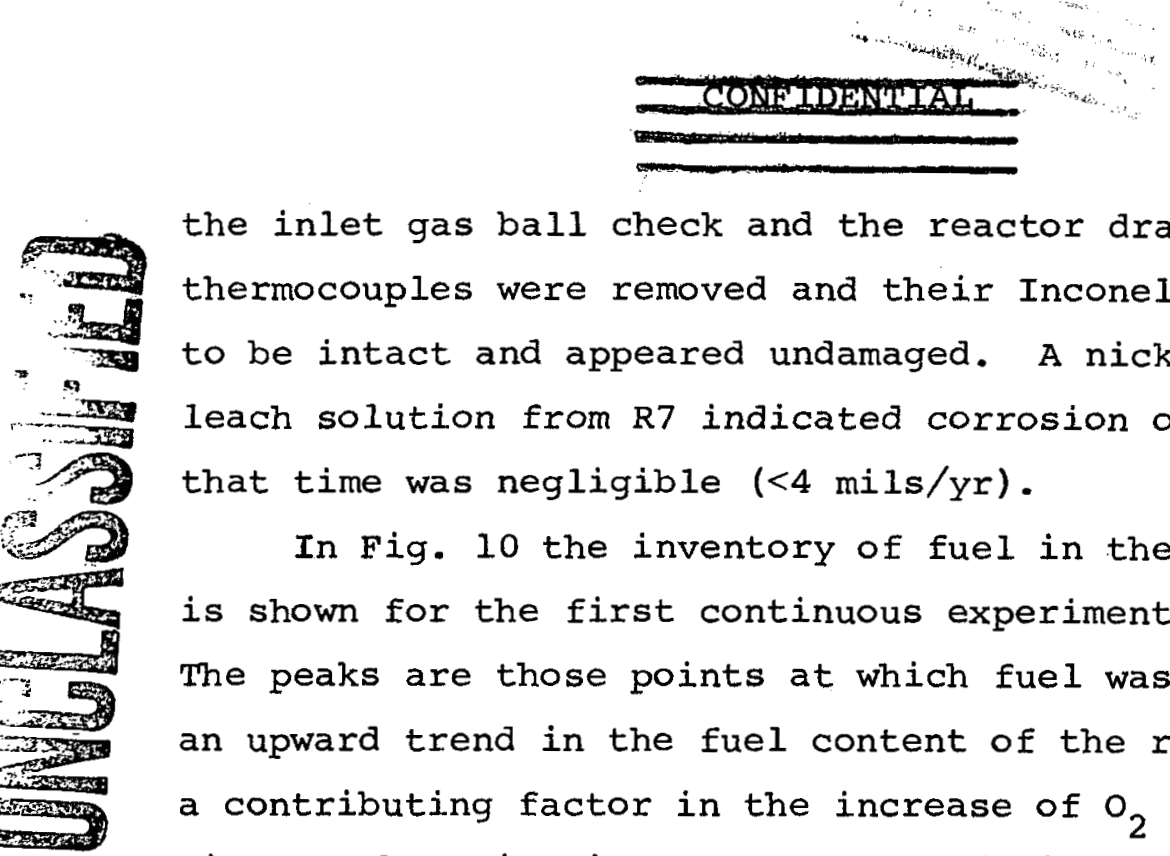

the inlet gas ball check and the reactor drain line. The bed thermocouples were removed and their Inconel sheathing was found to be intact and appeared undamaged. A nickel analysis of the leach solution from $R 7$ indicated corrosion of the burner up to that time was negligible ( $<4 \mathrm{mils} / \mathrm{yr})$.

In Fig. 10 the inventory of fuel in the oxidizer (as $\mathrm{kg} \mathrm{c}$ ) is shown for the first continuous experimental series (Runs 3-9). The peaks are those points at which fuel was charged. There is an upward trend in the fuel content of the reactor which may be a contributing factor in the increase of $\mathrm{O}_{2}$ utilization with time as shown in Fig. 8. However, during this period there was also a buildup of the product oxides $\left(\mathrm{U}_{3} \mathrm{O}_{8}\right.$ and $\left.\mathrm{Nb}_{2} \mathrm{O}_{5}\right)$ which possibly has a catalytic effect on the reactions and thus may increase $\mathrm{O}_{2}$ utilization and the $\mathrm{CO}_{2} / \mathrm{CO}$ ratio in the off-gas.

In Table 1 is shown carbon material balance for Runs R3 through R9. The balances were calculated from the volume and analysis of the off-gas and amount of carbon in the fuel feed.

The oxidation Runs R10 to Rl4, corresponding to the fluorination runs described below, were carried out in the usual manner with the exception of Run RI4 in which the bed material consisted of a higher proportion of 60-mesh ( $80 \% 60$ mesh, 10\% 90-mesh, $10 \% 120$ mesh) alumina. No appreciable difference was noted in fluidization quality during this run. The bed material from fluorination Runs RFlO and RFll were recycled to the oxidizer. After RF12, no bed material was recycled. During the course of R14, oxygen feed rate was varied to determine its effect on burning rate and oxygen utilization. As shown in Fig. 11, burning rate $(\mathrm{kg} \mathrm{C} / \mathrm{hr})$ increases but $\mathrm{O}_{2}$ utilization is lowered as the $\mathrm{O}_{2}$ feed rate increases. It appears that operating at

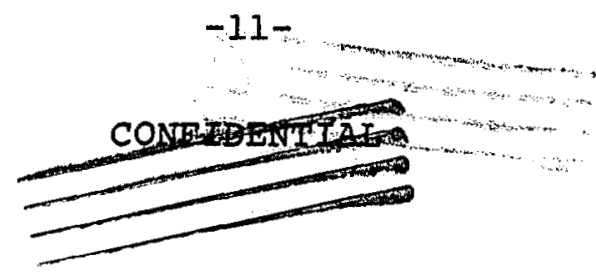




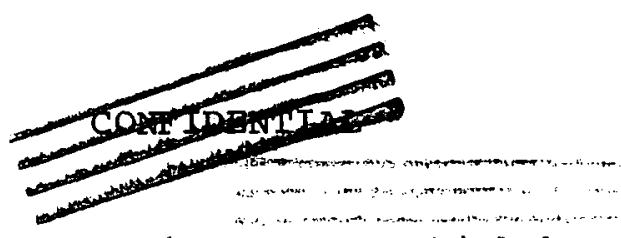

1.4 SCFM is a good compromise between-high burning rate and high oxygen utilization.

The performance of the porous metal filters in the oxidizer has been excellent and blowback of the filters was necessary only infrequently. The filter pressure drop has remained essentially constant since Run Rl.

Heat transfer coefficients from fluidized bed to reactor wall have been calculated for a typical pilot plant burning operation (R6). Necessarily, these coefficients are approximate. However, they do confirm the excellent heat transfer characteristics of similar fluidized bed systems ${ }^{3}$. The average value for this run was approximately $85 \mathrm{Btu} / \mathrm{hr}-\mathrm{ft} \mathrm{t}^{2}-{ }^{\circ} \mathrm{F}$. Heat release values were calculated from $\mathrm{CO}$ and $\mathrm{CO}_{2}$ analysis and gas feed measurements. The heat transfer area was assumed to be equal to the inside area of the 4-inch diameter section of the oxidizer

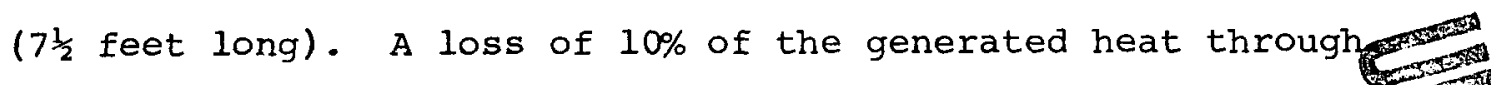
end effects was assumed. Temperature differences were calcu from bed centerline temperatures and outside wall temperature and averaged $54^{\circ} \mathrm{F}$.

\section{B. Leaching Results}

A total of 7 bed leaching experiments with nitric acid were carried out in the pilot plant. The bed material used was from the first nine pilot plant oxidation runs. Full bed recycle was employed in these burn-leach runs. The results of all the pilot $\mathrm{HNO}_{3}$ leaching experiments are shown in Tables II and III.

In the last oxidation run (R9) the fuel was reacted to completion after which the entire bed was leached in three batches (R9 L1, R9 L2, R9 L3). Because of the relatively high residual $U$ concentration in leach Runs $R 9 \mathrm{Ll}$ and $\mathrm{R} 9 \mathrm{~L} 2,2.0 \mathrm{~kg}$

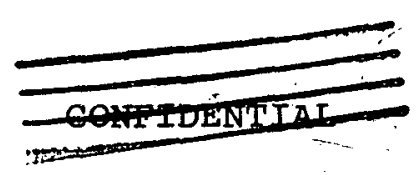




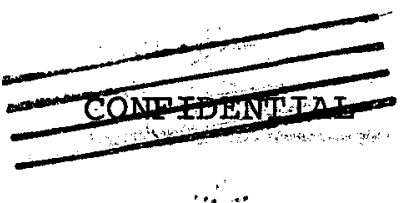

Antala

$\ldots$

ortions of these beds were releached. As shown in Table 2 only a marginal reduction of the residual $U$ content was obtained (from $0.54 \%$ to $0.43 \%$ ).

The average leaching time per run (including wash) was approximately three hours; however, a much longer bed drying time ( 8 to 24 hours) was necessary. The long drying time was, in part, due to the fact that the drying gas was not preheated and, since a glass leaching column was used, the heat input through the column wall was low.

As shown in Table 2, an over-all uranium recovery of only $97.4 \%$ was obtained by leaching with nitric acid which indicates that full $U$ recovery requires further leaching steps with a mixture of hydrofluoric and nitric acids. In such a mixed acid leaching step it is desirable to keep the totalamount of HF as low as possible in order to reduce the aqueous waste volume. Table 3 shows the results of a number of bench-scale mixed acid leaching experiments carried out in $1 "$ Teflon-lined columns in which an air lift pump was used to recirculate the leach solution continuously. The concentration of all leaching solutions were $10 \mathrm{M} \mathrm{HNO}_{3}$ and $5 \mathrm{M} \mathrm{HF}$. The volume of the leachant was varied to change the $F / N b$ ratio. As shown in Table 4 , an $F / N b$ ratio as low as 11.5 was sufficient to dissolve all the No and most of the $U$ at $112^{\circ} \mathrm{C}$. It should be noted that if the mixed acid leaching step is carried out using bed material directly after discharge from the oxidizer, thus bypassing the $\mathrm{HNO}_{3}$ step, the resulting solution is unstable since precipitates form upon cooling.

Because of equipment and time limitations, only one engineering-scale mixed acid leaching experiment was carried

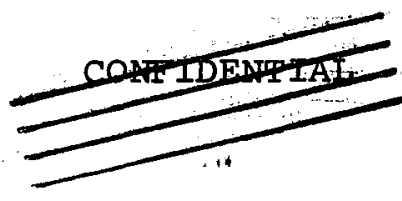




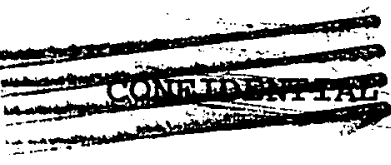

$\therefore$ -

out to confirm the bench-scale results. A total of $3 \mathrm{~kg}$ of bed material from Run R9 L3, previously $\mathrm{HNO}_{3}$ leached, were charged to a 4-inch i.d. Teflon-lined column and contacted with recirculating mixed acid at $105^{\circ} \mathrm{C}$ for nine hours after which the bed was washed with $500 \mathrm{ml}$ of $\mathrm{H}_{2} \mathrm{O}$. As shown in Table 4, both the $U$ and $N$ b concentrations in the bed were reduced to negligible levels while the mol ratio of $\mathrm{F} / \mathrm{Nb}$ in the leach liquor was 12.15 .

\section{Fluorination}

The bed material for the fluorination runs was prepared in oxidation Runs R10 to R14. These oxidation runs generally were of longer duration than those previously carried out because the capacity of the fluorinator was higher than that of the leach system. The corresponding fluorination runs are labelled RF10, RFll etc.

The first four oxidation runs (R10 to R13) were part of a single series in which the oxidizer always contained an inventory of unburned fuel (as in Runs R3 to R9). At the end of R13 the fuel inventory was completely reacted and the entire bed was transferred to the fluorinator for Run RF13. Following this experimental series, a single oxidation run was made with a fresh alundum bed. During the oxidation Rover fuel was added periodically, however, no bed material was discharged or introduced during the run. After oxidation the entire bed was transferred to the fluorinator as the charge for Run RF14. This change in procedure was made so that a material balance based on the oxidizer feed could be made on a single run (see below).

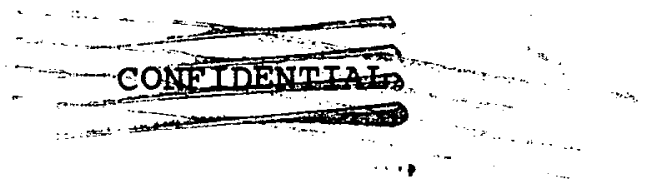


The results of the five fluorination runs (RFl0 to RF14) are shown in Table $\mathrm{V}$. The recovery of $\mathrm{U}$ and $\mathrm{Nb}$ in the first run (RF10) was almost negligible and apparently the bulk of the $\mathrm{UF}_{6}$ and $\mathrm{NbF}_{5}$ evolved remained as holdup in the product recovery system. The removal of $U$ from the alundum bed material was high in all runs except RFlo in which the fluorination time was probably too short. In Runs RF13 and RFl4 the fluorine feed concentration was increased from 25 to $50 \%$ in the course of the fluorination which effected a substantial increase in the rate of reaction and thereby reduced the time necessary to reach satisfactory residual $U$ concentrations $(<500 \mathrm{ppm})$. However, the residual $\mathrm{Nb}$ concentration was quite high in all runs. This may be due to the tendency for $\mathrm{Mb}_{2} \mathrm{O}_{5}$ to form fines which are easily elutriated from the fluid bed into the cooler upper section of the reactor.

The off-gases of Run RFl4 were analysed continuously for fluorine and a plot of the off-gas composition vs time for this run is shown in Fig. 12. As shown, the $F_{2}$ concentration in the off-gas was small (2 to $4 \%$ ) for the first two hours and was independent of the inlet fluorine concentration which was varied between 25 and 50\%. The $\mathrm{F}_{2}$ utilization during this period was at least $75 \%$. Subsequently, the $\mathrm{F}_{2}$ utilization rapidly dropped and remained at a low value for the duration of the run. It is estimated the $U$ concentration in the bed at this point was below $1 \%$. The actual $U$ concentration in the bed at the breakoff point will be determined in future runs.

Upon completion of RFl4, the bed material was drained from the fluorinator and all the pilot plant vessels examined to determine the holdup of uranium in the system. The UF 6 cold trap and the $\mathrm{NbF}_{5}$ condenser were washed and the washings sampled. The

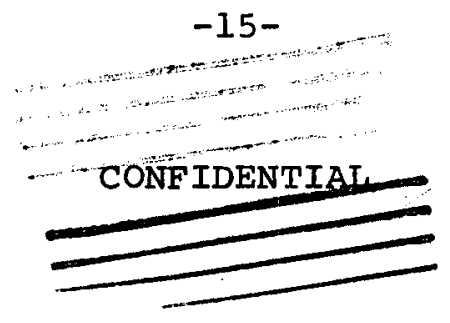




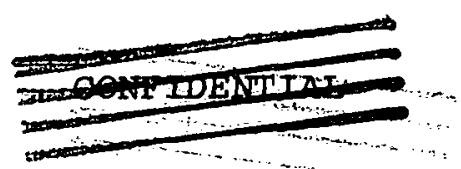

heads of the NaF traps were removed and NaF samples were taken. The heads of both reactors were removed and the reactors were examined to insure that all the bed material had been removed. Except for a small amount of fines $(\sim 50 \mathrm{~g})$ found on the horizontal surfaces at the top, both reactors were essentially clean and in good condition.

The $U$ holdup found in the system after RFl4 is shown in Table VI which also presents a uranium material balance for all the fluorination runs and the over-all $\mathrm{U}$ recovery. The balance is based on the analysis of the bed material charged to the fluorinator after oxidation.

In addition, a further material balance was made for Run RF14 on the basis of the analysis* of fuel charged to the oxidizer in Run R14. This balance was made on two assumptions: 1) that of the $124 \mathrm{~g}$ of $\mathrm{U}$ found in the low temperature NaF trap (Table VI) a proportionate amount was from RFl4 (i.e. $57 \mathrm{~g}$ ), and 2) that the remainder of the $U$ holdup in the system was constant after the first four oxidation-fluorination runs (RF10 to RF13). As shown in Table VII, a satisfactory balance was obtained.

A niobium material balance was made on the basis of the fuel analysis as shown in Table VIII for Runs RFlo to RF14. Unfortunately, a satisfactory $U$ material balance for Runs (5) Find and $\cdots$ Fis a 1,

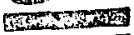

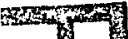
mingesis Thents Pins RF10 to RF13 could not be made on the basis of the fuel analysis. since the oxidizer always contained a fuel inventory in these runs, only a single over-all balance was possible on this basis. The fuel analysis indicated that over $1 \mathrm{~kg}$ of $\mathrm{U}$ was missing.

* these analyses were received with the fuel shipment and gave the $\mathrm{U}$ and $\mathrm{Nb}$ content of each fuel rod in the shipment.

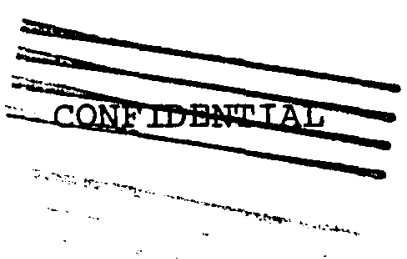



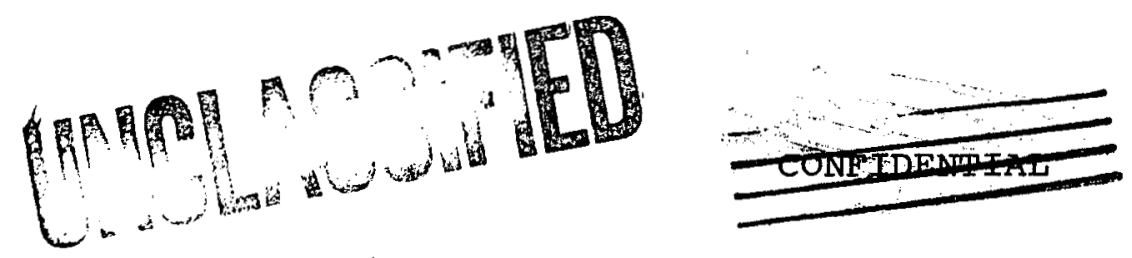

Since only a relatively small $U$ holdup was found in the system after Run RFl4 (Table VI) and in view of the excellent balance obtained based on the bed analyses, it was concluded that a number of the uranium analyses of the fuel rods used in these runs were in error.

While the attrition of the alumina bed did not seem to be excessive as shown by screen analysis after fluorination (Fig. 13), a small quantity of very fine material had built up by Run RFl2. Thus, this bed and the bed from RFl3 were not recycled. The fine material ( -200 mesh) from Run RF12 was found to have a fluoride concentration of $2.5 \%$ while the bed as a whole contained $0.32 \%$. This amount of fluoride in the fines can only be accounted for by conversion of some $\mathrm{Al}_{2} \mathrm{O}_{3}$ to $\mathrm{AlF}_{3}$. However, the over-all fluoride concentration is low and apparently does not present a corrosion problem in the oxidation upon recycle since the nickel content of the bed was found to be only $45 \mathrm{ppm}$ at the end of Run RFll. This corresponds to an average corrosion rate of $<5 \mathrm{mils} /$ year for both reactors (see section $\mathrm{D}$ ).

No operating difficulties were experienced in the U recovery system and, with the exception of the first run (RF10), fairly good separations between $\mathrm{NbF}_{5}$ and $\mathrm{UF}_{6}$ were made as shown in Table V. Contemplated changes in the operation of the $\mathrm{NbF}_{5}$ condenser should reduce the U loss to that trap.

The sintered metal filters in the fluorinator have performed very well. On several occasions it was necessary to increase the blowback pulse rate from 30 per hour to 120 per hour in order to prevent a buildup of filter pressure drop. There has been no detectable permanent increase in the fluorinator filter pressure drop (15 - 20 inches of water) from the end of Run RFlo to RFl4.

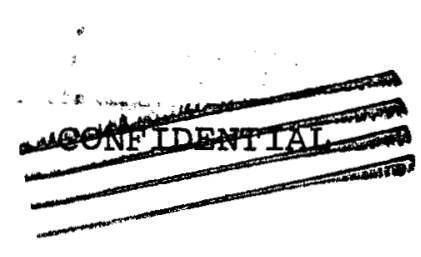




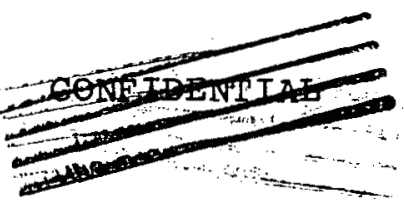

It was found advisable to use pulsed filter blowback throughout the entire course of a run so that only a small amount of fines were blown back during any pulse since the sudden return to the top of the bed of a large amount of fines resulted in a temperature excursion of $\sim 100^{\circ} \mathrm{C}$ on two occasions.

\section{Corrosion}

Literature sources report that nickel is a good material of construction for high temperature fluorine and oxygen 4,5 and, although corrosion samples in both the oxidizer and fluorinator have not yet been removed, indications are that corrosion in both reactors is light (see sections IIIA and IIIC).

However, it was found in bench-scale tests that the presence of a moderate amount of fluoride salts in the bed will greatly accelerate the corrosion rate during oxidation. Penetration rates up to $1 \mathrm{mil} / \mathrm{hr}$ with Nickel 201 have occurred when an alundum bed containing 1 wt $\% \mathrm{AlF}_{3}$ was fluidized with $100 \% \mathrm{O}_{2}$ at a wall temperature of $725^{\circ} \mathrm{C}$. The attack appears to be strongly temperature dependent for at $650^{\circ} \mathrm{C}$ the corrosion coupon gained weight.

In Fig. 13 is plotted the weight change $/ \mathrm{cm}^{2}$ of Inconel and Nickel 201 corrosion coupons vs cumulative oxidation time in a bench-scale (2-inch i.d.) oxidizer. In these experiments Rover fuel was oxidized in a fluidized alundum bed, the bed transferred to a bench-scale fluorinator and contacted with $\mathrm{F}_{2}$ for one hour. Following fluorination the bed was returned to the oxidizer and a new cycle of oxidation-fluorination. A total of five complete oxidation-fluorination cycles were carried out. Although both samples exhibited an over-all weight gain, longer term tests are clearly necessary before conclusions oan be drawn. Thus, un-

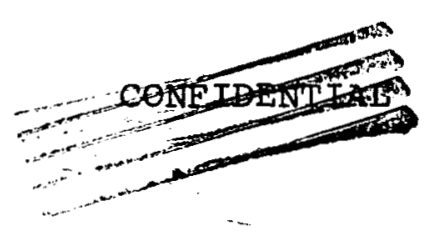




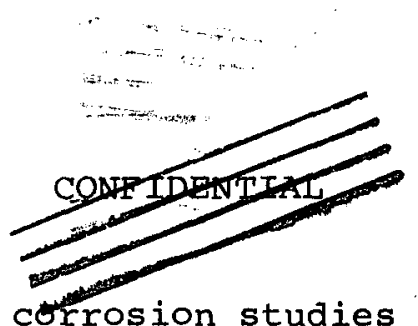

til more definitive corrosion studies are carried out, it has been recommended that the preliminary flowsheet of the burnfluorination process specify that the alundum bed material not be recycled.

\section{Full-scale Plant Design}

Two preliminary flowsheets for the burn-leach and burnfluorination processes have been prepared at $\mathrm{ORNL}^{6,7}$. Briefly, both flowsheets specify a continuous fluid bed oxidizer followed by, depending on the process, a continuous fluorinator or two Teflon-lined batch leaching vessels. The authors feel that of the two processes the burn fluorination route is more attractive for the following reasons.

1. It is a completely dry process, thus criticality problems are reduced to a minimum.

2. The burn-leach process will generate moderate amounts of aqueous fluoride containing wastes which must be stored or further processed. In contrast, the wastes from the fluoride volatility route will be of much lower volume and can be easily handled or stored.

3. There may be some difficulty in the fabrication of Teflonlined leach equipment.

4. The aqueous alternate requires several more process steps than the fluoride volatility scheme and is a more complex operation.

V. Conclusions

From the results reported above the following conclusions have been made:

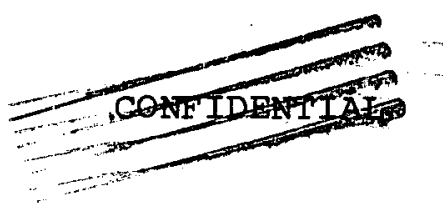




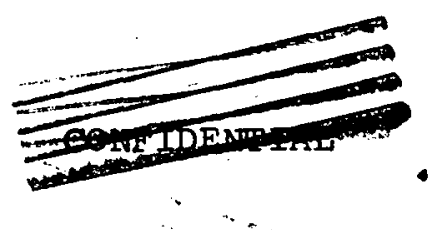

1. Continuous fluid bed oxidation of Rover fuel is a practical and attractive head end reprocessing step for such fuel.

2. Reaction and temperature control in both the oxidizer and fluorinator have been excellent and both units can be operated safely within wide limits of superficial gas velocity, gas composition, temperature, bed composition and bed particle size. 3. Satisfactory recovery of uranium from the oxidized bed material via fluorination can be readily obtained (residual $U$ concentration in the bed $<500 \mathrm{ppm}$ ).

4. Fairly good separation of $\mathrm{UF}_{6}$ from $\mathrm{NbF}_{5}$ has been achieved in the volatile product recovery system.

5. Complete recovery of $U(>99 \%)$ from the bed via aqueous leaching will require contacting the bed with a mixture of $\mathrm{HF}$ and $\mathrm{HNO}_{3}$ in which the mol ratio of fluoride to $\mathrm{Nb}$ is 11.5 or greater. Such solutions will dissolve all the $\mathrm{Nb}_{2} \mathrm{O}_{5}$ and presumably that uranium which previously migrated into the NoC liner.

6. Bed material can be transferred readily between vessels. 7. The performance of the porous metal filters in the and fluorinator has been satisfactory in all respects
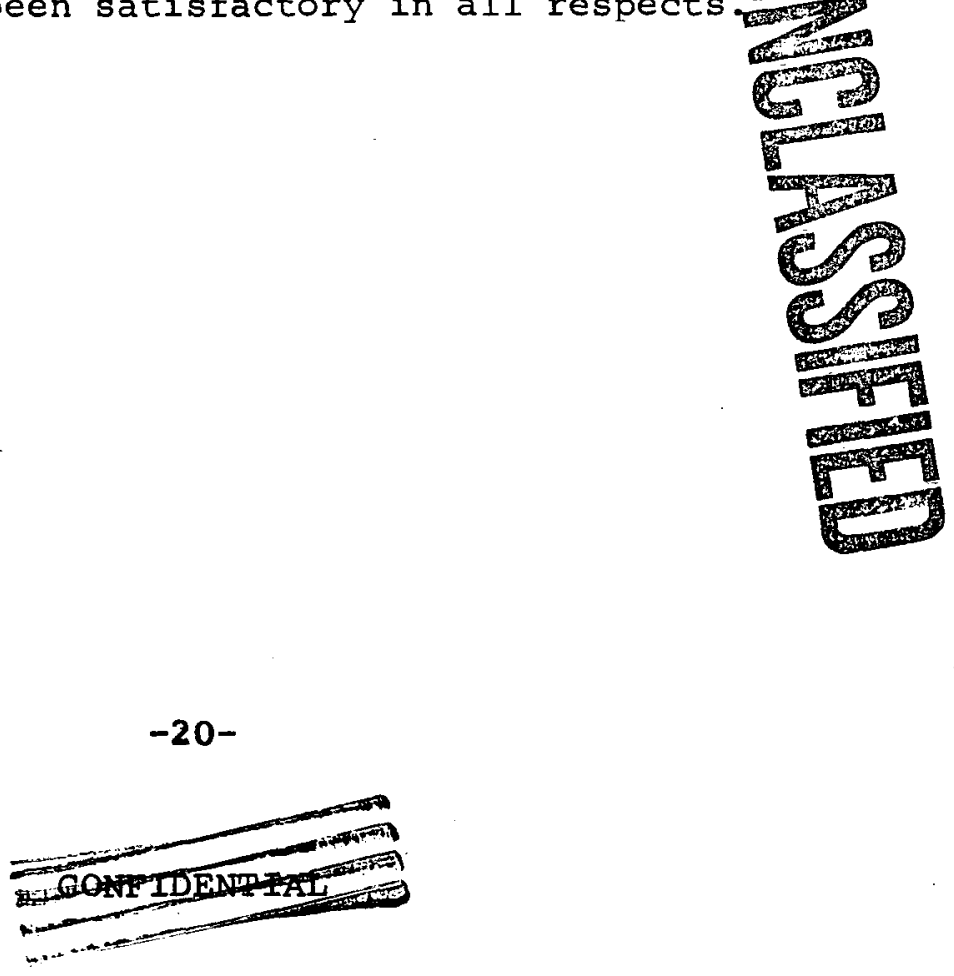


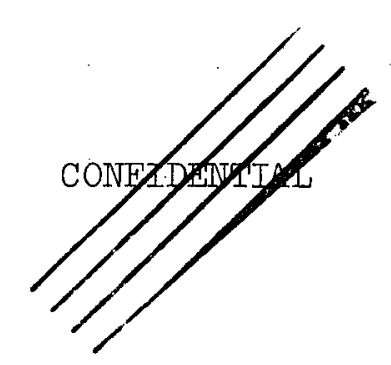

References :

1. Reilly, J. J., Regan, W. H., Wirsing, E., and Hatch, L.P., Ind. and Eng. Chem. Process Design and Development $\underline{2}$ (1963) 127-133.

2. Pashley, J. H. and Kaufman, H. L., ORGDP Report K-L-1859.

3. Ziegler, E. N., Brazelton, W. T., Ind. and Eng. Chem. Process Design and Development $\underline{2}$ (1963 276-281).

4. Reactor Development Progress Report, ANL-6885, p. 61.

5. Steindler, M. J., and Vogel, R. C., ANL-5662.

6. Nicholson, E. L., ORNL Flowsheet E-57705.

7. Nicholson, E. L., ORNL Flowsheet E-57683.
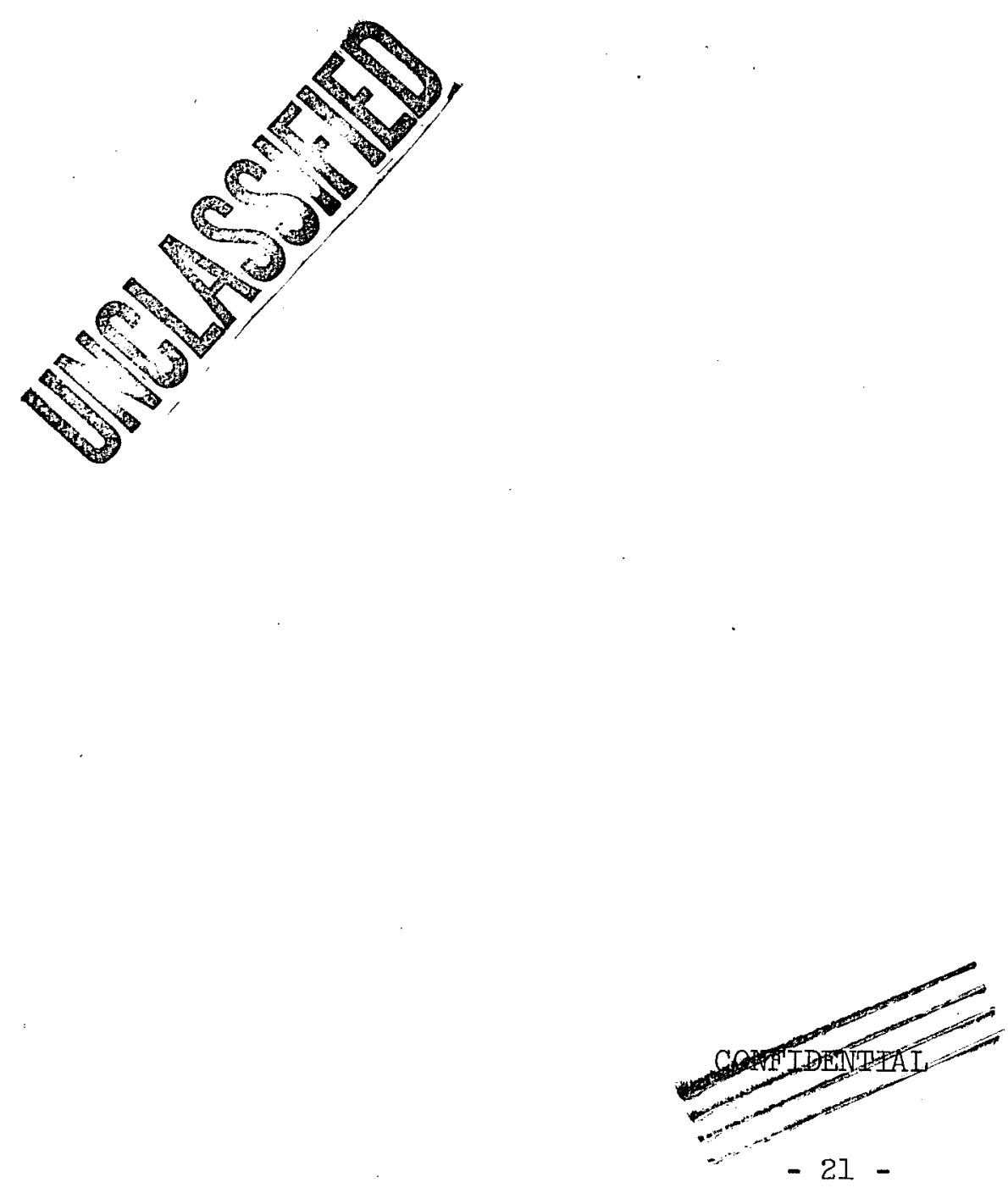


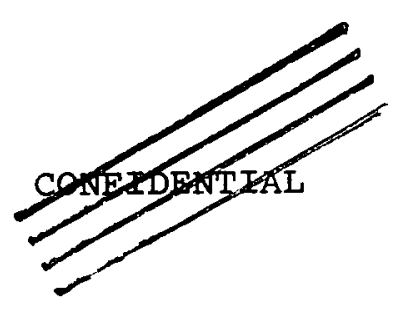

TABLE I

Carbon Balance R3 Through R9

Run

R3

R4

R5

R6

R7

R8

R9

\section{Charged (a)}

4,226

2,982

2,996

2,390

2,392

12,597

0000

Removed (q) as CO and $\mathrm{CO}_{2}$

2,688

3,460

2,509

2,042

3,049

12,508

1,674

Carbon Fines Recovered

30

Carbon on Bed Removed from Oxidizer (at $0.095 \%$ )

21

Total

27,583

27,981

Carbon Balance $=\frac{27,981}{27,583} \times 100=101.5 \%$
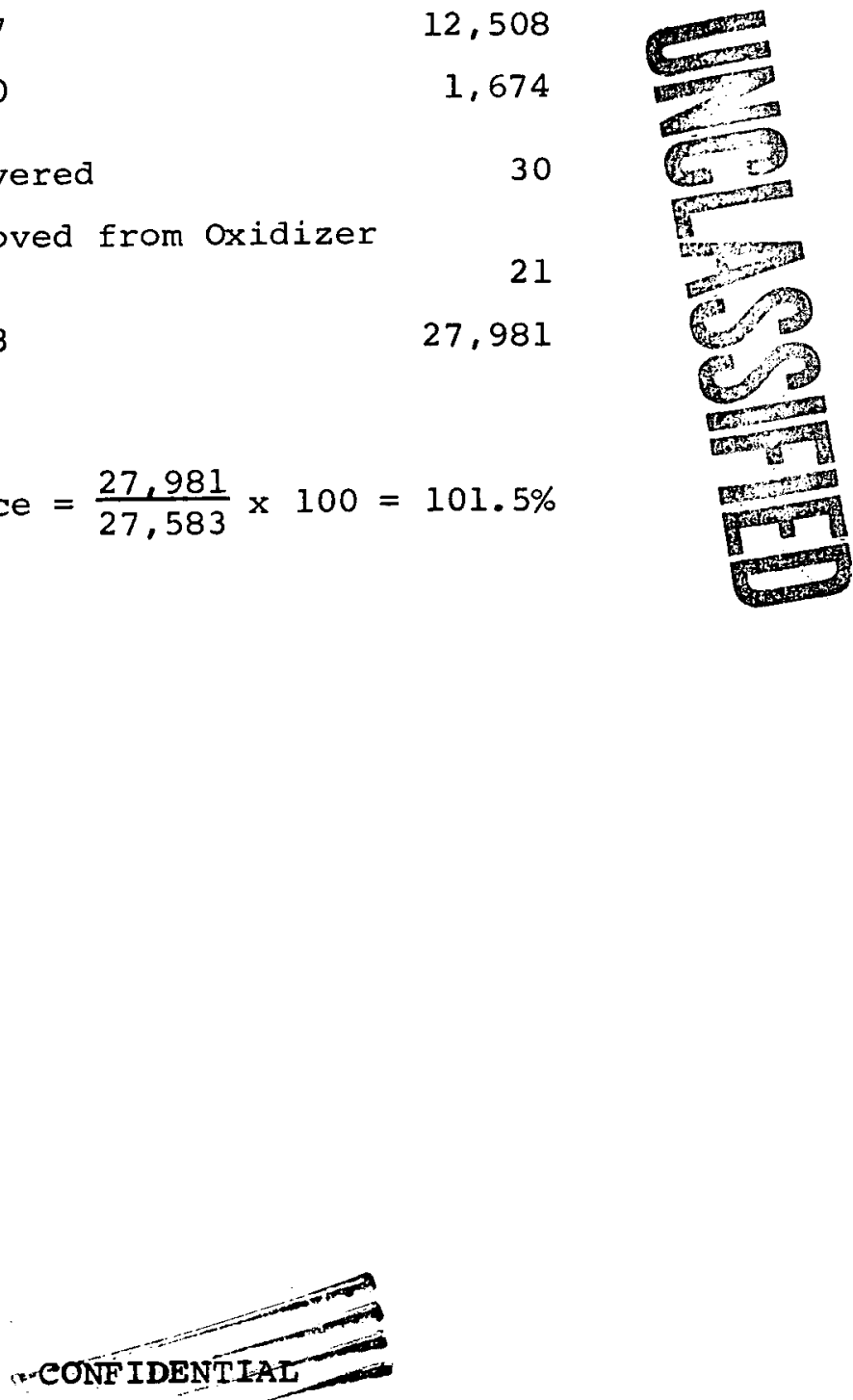


\begin{abstract}
Bed
\end{abstract}
Bed

Wt.
$\mathrm{Kg}$

4.148

$\sim 5.200$

$\sim 3.750$

2.169

7.722

11.690

5.945

0.589

Releach of Beds R9Ll and R9L2

$\begin{array}{lllll}\text { R9L1 } & 2 & 2 & 2.000 & 0.5480 \\ \text { R9L2 } & 2 & 2 & 2.000 & 0.541\end{array}$

Over-all Recovery from R9L1 and R9L2

R9L1

R9L2

10.5

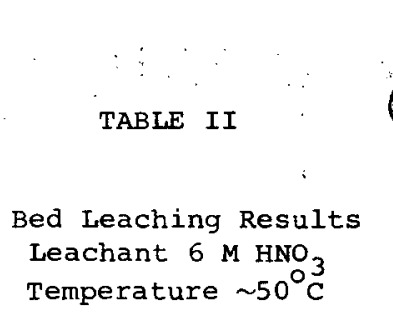

Initial U Conc. in Bed Wt.\%.

$$
3.33
$$

4.0

6.1

8.0

10.5

13.4

13.2

9.3

0.541

Leachant $6 \mathrm{M} \mathrm{HNO}_{3}$

Temperature $\sim 50^{\circ} \mathrm{C}$

$\mathrm{Nb}_{2} \mathrm{O}_{5}$ Conc.

in Bed Wt. $\%$

$$
3.7
$$

6.57

8.6

6.5

10.4

11.7

15.4

13.0

$v$ in

Leachate 9

136

204

204

175

815

1,570

783

55

$\begin{array}{ll}2.31 & 0.433 \\ 2.65 & 0.415\end{array}$

U Conc. in Leached Bed

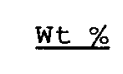

$0.051 \%$

0.200

0.290

0.300

0.548

0.541

0.429

0.170

2.65

0.415

0.433

0.415

$\mathrm{U}$

Recovery

From Bed \%

98.5

98.3

98.1

98.7

95.6

96.7

97.3

98.6

$\vdots$

21. 1

23.3

है:

96.7

97.4

Over-all Uranium Recovery of All Runs** $=\frac{\text { Total U Leached }}{\text { Total U Leached }+ \text { Residual on Bed }} \times 100=\frac{3,962}{4,068} \times 100=97.4 \%$

Notes: * Bed held up in bottom of bed receiver vessel and leached at conclusion of oxidation series.

** Assuming final bed residual $U$ content of Bed $R 9$ could be reduced to $0.43 \% \mathrm{U}$ as in Leach $\mathrm{R} 9 \mathrm{~L} 1$. 


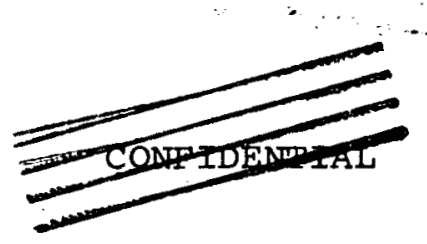

TABIE III

Uranium Material Balance Rl Through R9 Based on Analysis of Fuel Charged to Oxidizer

Charged

56 elements

Recovered

R2L

R5L

R7L

R8L

R9L1

R9L2

R9L 3

Holdup leach*

Residual U in Leached Beds**

R8I

R9L1

R9L2

R9L3

Samples Removed from System

RI

R2

R5

R5L

R8

R9

Misc. Samples

TOTAL U ACCOUNTED FOR

$$
\text { Uranium Balance } \frac{4372}{4702} \times 100=92.9 \%
$$

* Bed held up in bottom of bed receiver vessel

** Before releaching R9Ll and R9L2

\section{Uranium $\mathrm{g}$} 4702

136

204

224

175

815

1570

783

55

37

53

22

5

55

40

11

138

46

4372

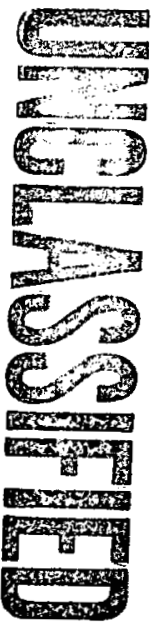

andisests 


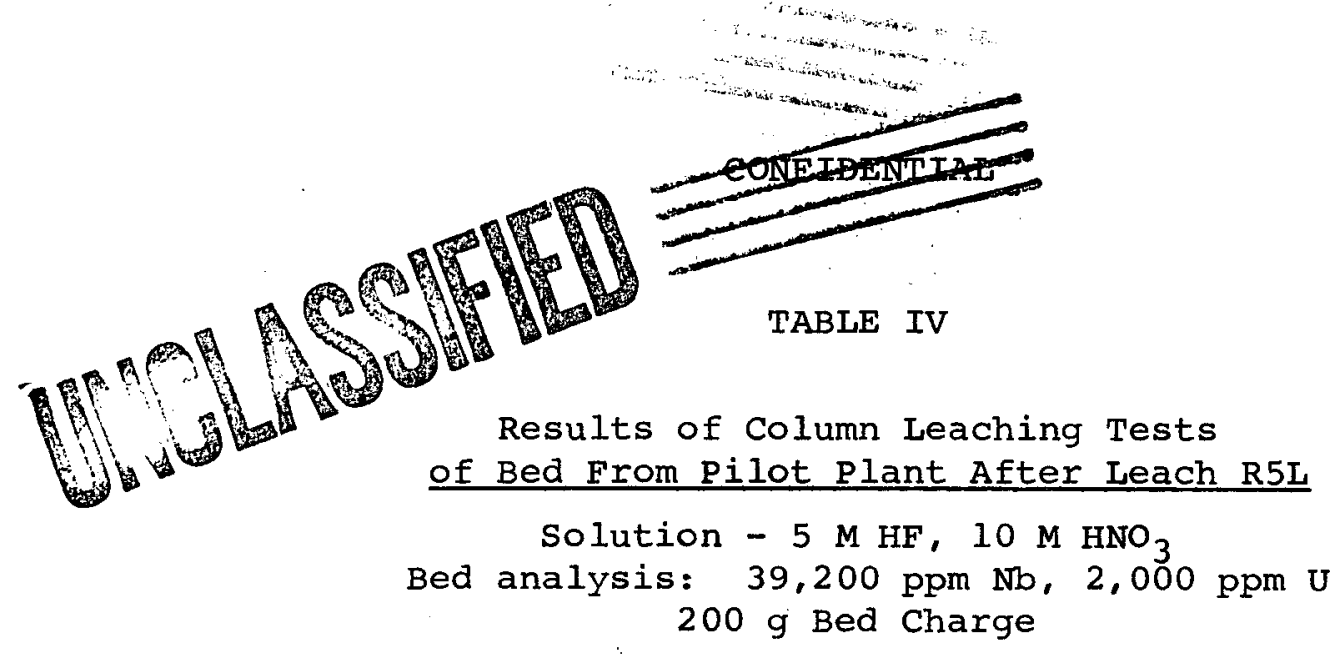

\begin{tabular}{|c|c|c|c|c|c|}
\hline \multirow[b]{2}{*}{ Run No. } & \multirow[b]{2}{*}{$\mathrm{F} / \mathrm{Mb}$ Ratio } & \multirow[b]{2}{*}{ Temperature, ${ }^{\circ} \mathrm{C}$} & \multirow[b]{2}{*}{ Time, $\mathrm{hr}$} & \multicolumn{2}{|c|}{ Residual ppm } \\
\hline & & & & $\mathrm{U}$ & $\mathrm{Nb}$ \\
\hline 1 & 46 & 112 & $I$ & 275 & 0 \\
\hline 2 & 46 & 95 & 1 & 215 & 8,000 \\
\hline 3 & 26 & 90 & 2 & 155 & 9,500 \\
\hline 4 & 18 & 112 & 3 & 40 & 200 \\
\hline 5 & 46 & 100 & 1 & 64 & 3,500 \\
\hline 6 & 24 & 100 & 3 & 56 & 2,500 \\
\hline 7 & 16 & 100 & 3 & 18 & 3,600 \\
\hline 8 & 17.5 & 112 & 3 & 52 & 300 \\
\hline 9 & 17.5 & 112 & 6 & 50 & 0 \\
\hline 10 & 11.5 & 112 & 6 & 52 & 0 \\
\hline
\end{tabular}

Mixed Acid Leach of $3 \mathrm{Kg}$ Bed From R9L 3

$5 \mathrm{M} \mathrm{HF}-10 \mathrm{MHNO}_{3}$

Initial $\mathrm{Nb}$ Concentration wt. \%

11.3

Initial U Concentration ppm

4290

Final No Concentration ppm

20

Final U Concentration ppm

52

F/No mol Ratio in Leach Solution

12.15

No in Leach Liquor $\mathrm{g}$

$\mathrm{U}$ in Leach Liquor $\mathrm{g}$

350.18

12.57

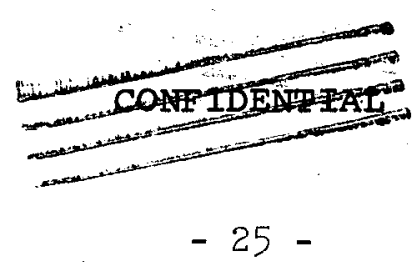


TABLE V

\section{Pilot Plant Fluorination Results}

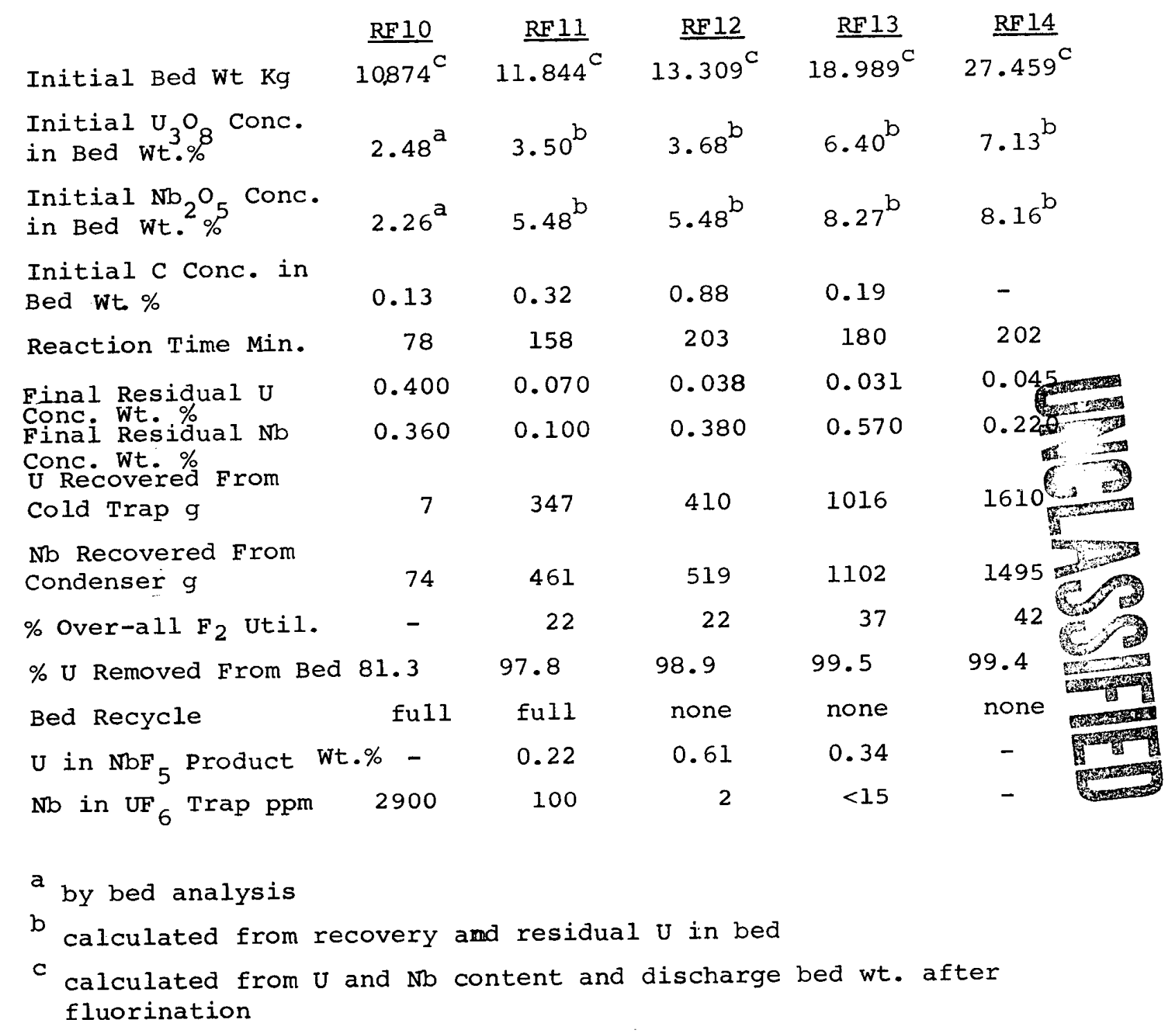

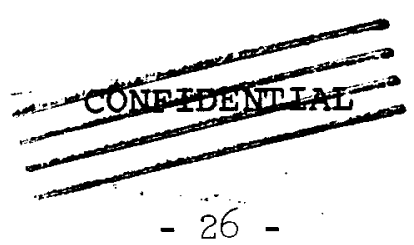




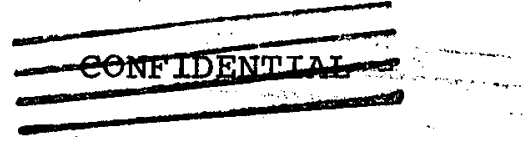

TABLE VI

Material Balance RF10 - RF14

Based on Analysis of Bed Material Charged to Fluorinator

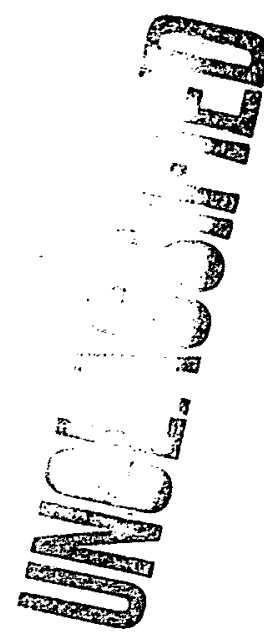

RF 10
RF 11
RF 12
RF 13
RF 14
Item

Initial U

Conc. by

Bed Analysis

Wt $\%$

$\underline{\mathrm{Kg} \mathrm{U}}$

2.08

0.226

2.18

0.260

3.02

0.402

6.03

1.145

6.35

$\underline{1.745}$

Total Charge

3.778

Item

$\underline{\mathrm{Kq}}$

1 Total U Recovered from UF Trap 3.390

$2 \mathrm{U}$ in $\mathrm{UF}_{6}$ Cold Trap Washings 0.135

$3 \mathrm{U}$ in Low Temperature NaF Trap 0.124

$4 \mathrm{U}$ in $\mathrm{NbF}_{5}$ Condenser Washings 0.001

$5 \mathrm{U}$ in High Temperature NaF Trap 0.009

$6 \mathrm{U}$ in Fines at Top of Fluorinator 0.008

$7 \quad \mathrm{U}$ in Scrubber Solutions 0.002

8 Residual $U$ in Bed Material $\quad 0.020$

$9 \mathrm{U}$ in $\mathrm{NbF}_{5}$ Product $\quad 0.020$

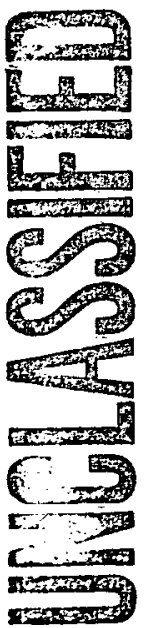

Total U Accounted For

3.709

Total U Charged to Fluorinator $\quad 3.778$

Material Balance $\frac{3709}{3778} \times 100=98.2 \%$

U Recovery*

$\underline{\mathrm{Kq}}$

U Recovered (Items $1,2,3,4,5,7,9$ ) 3.681

U Loss (Items 6,8 )

0.028

U Recovery $\frac{3.681}{3.709} \times 100=99.2 \%$

$$
\frac{3.681}{3.709}
$$

*All the $U$ evolved as $\mathrm{UF}_{6}$ from the fluorinator is considered recoverable.

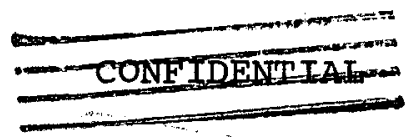




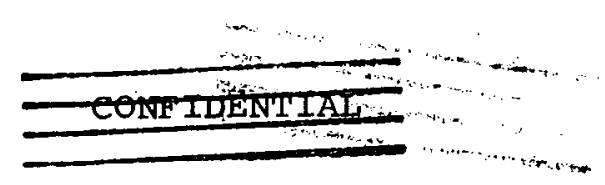

TABLE VII

Uranium Material Balance for Run RFl4 -

Based on Analysis of Fuel Charged to Oxidizer

$\begin{array}{lc}\text { Total U Added } & \underline{\mathrm{Kg}} \\ \text { U Recovered from UF }{ }_{6} \text { Cold Trap } & 1.764 \\ \text { *U in Low Temperature NaF Trap } & 1.610 \\ \mathrm{U} \text { in Oxidizer Bed Samples } & 0.057 \\ \mathrm{U} \text { in NbF }{ }_{5} \text { Product } & 0.030 \\ \mathrm{U} \text { Residue in Bed } & 0.006 \\ & 0.010 \\ \text { Material Balance - } \frac{1713}{1764} \times 100=97.1 \% & 1.713 \\ \text { *Estimated proportionate amount of } \mathrm{U} \text { in this trap } \\ \text { from RF14. }\end{array}$
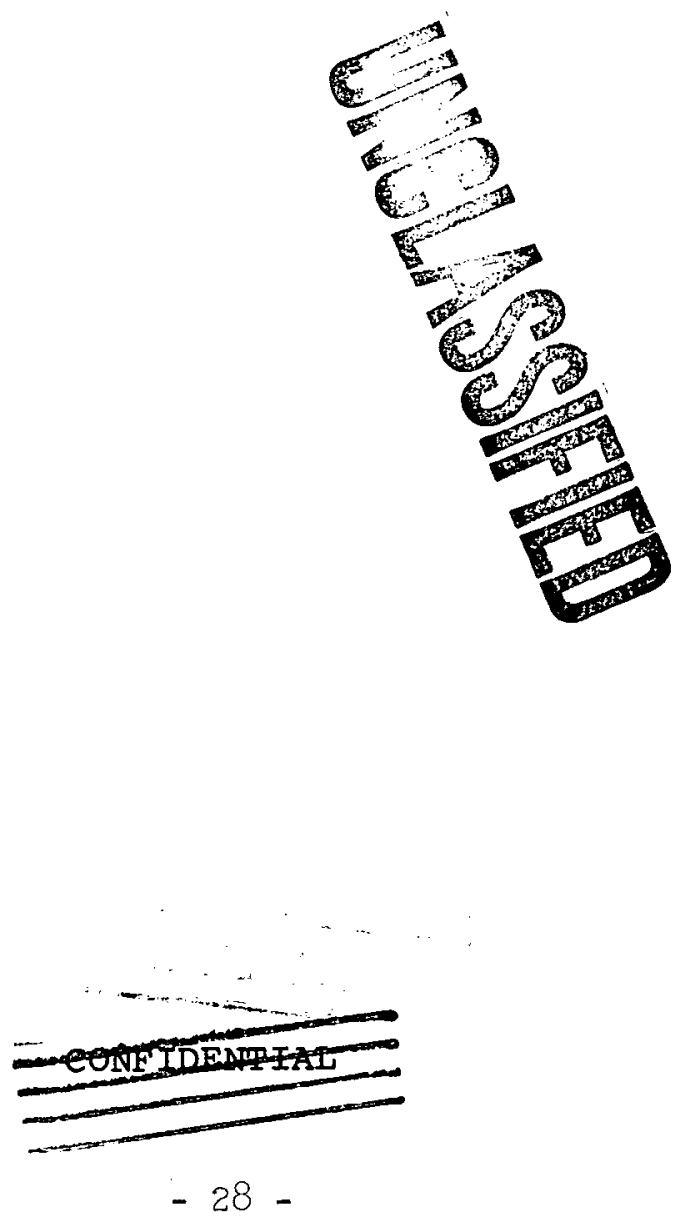


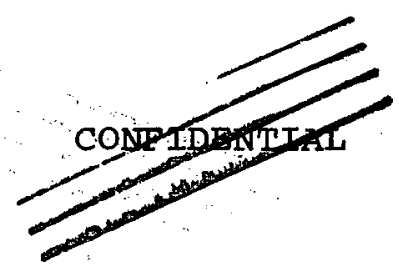

TABIE VIII

\section{Niobium Material Balance Based on Fuel Analyses \\ Runs RF10 to RF 14}

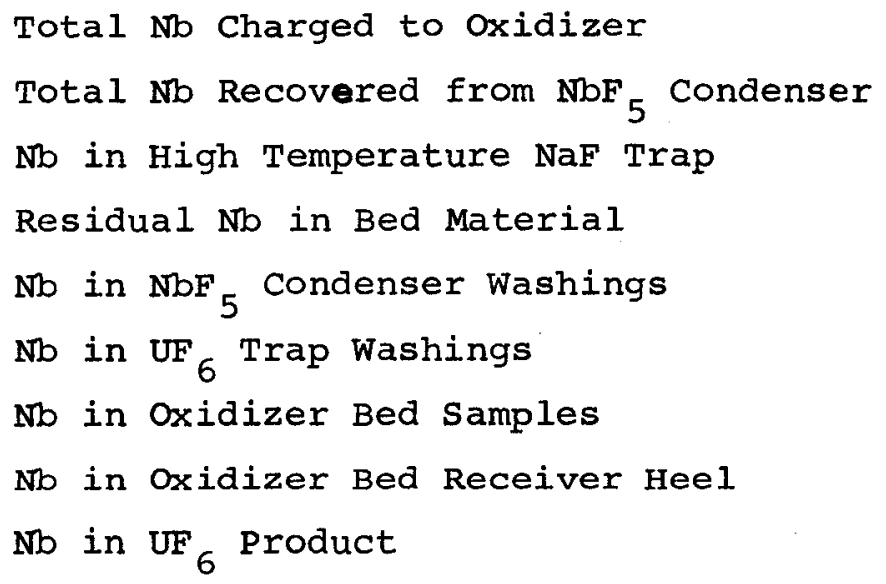

$\underline{\mathrm{Kq}}$

4.374

3.651

0.300

0.189

0.013

0.001

0.054

0.060

negligible
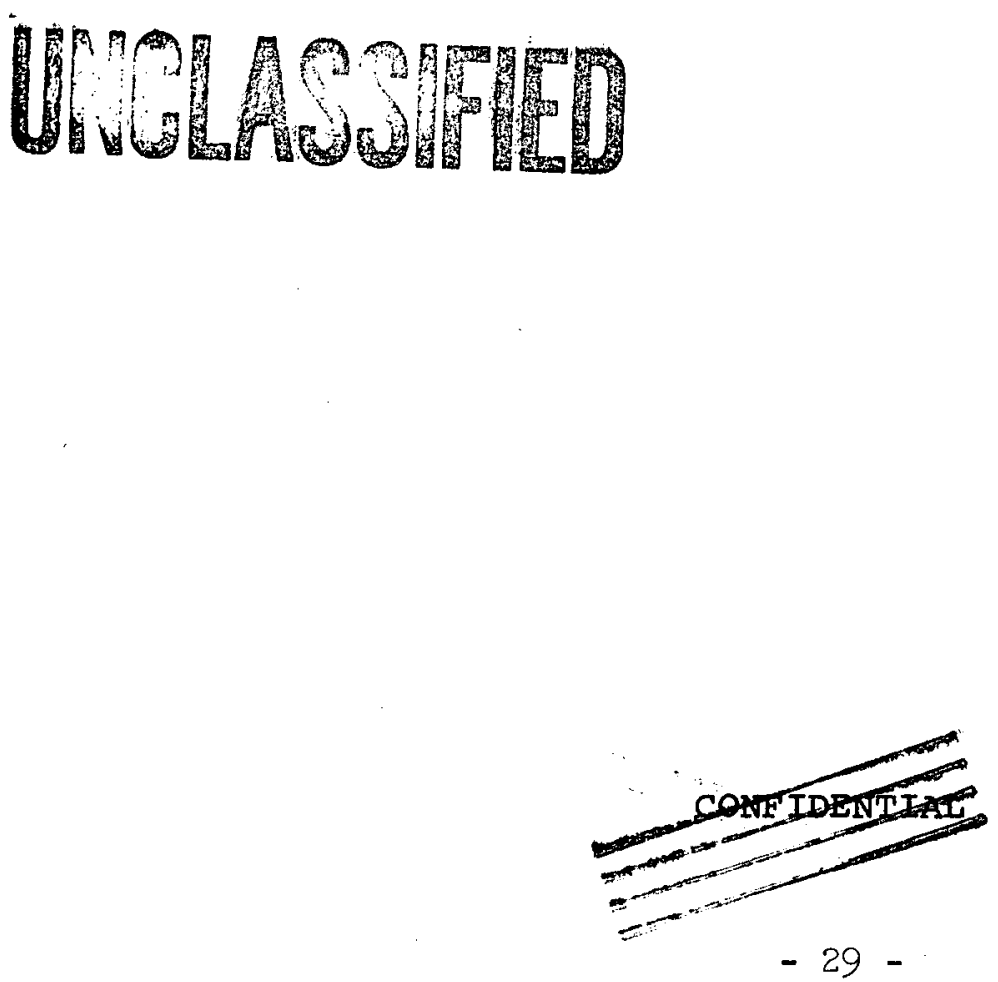


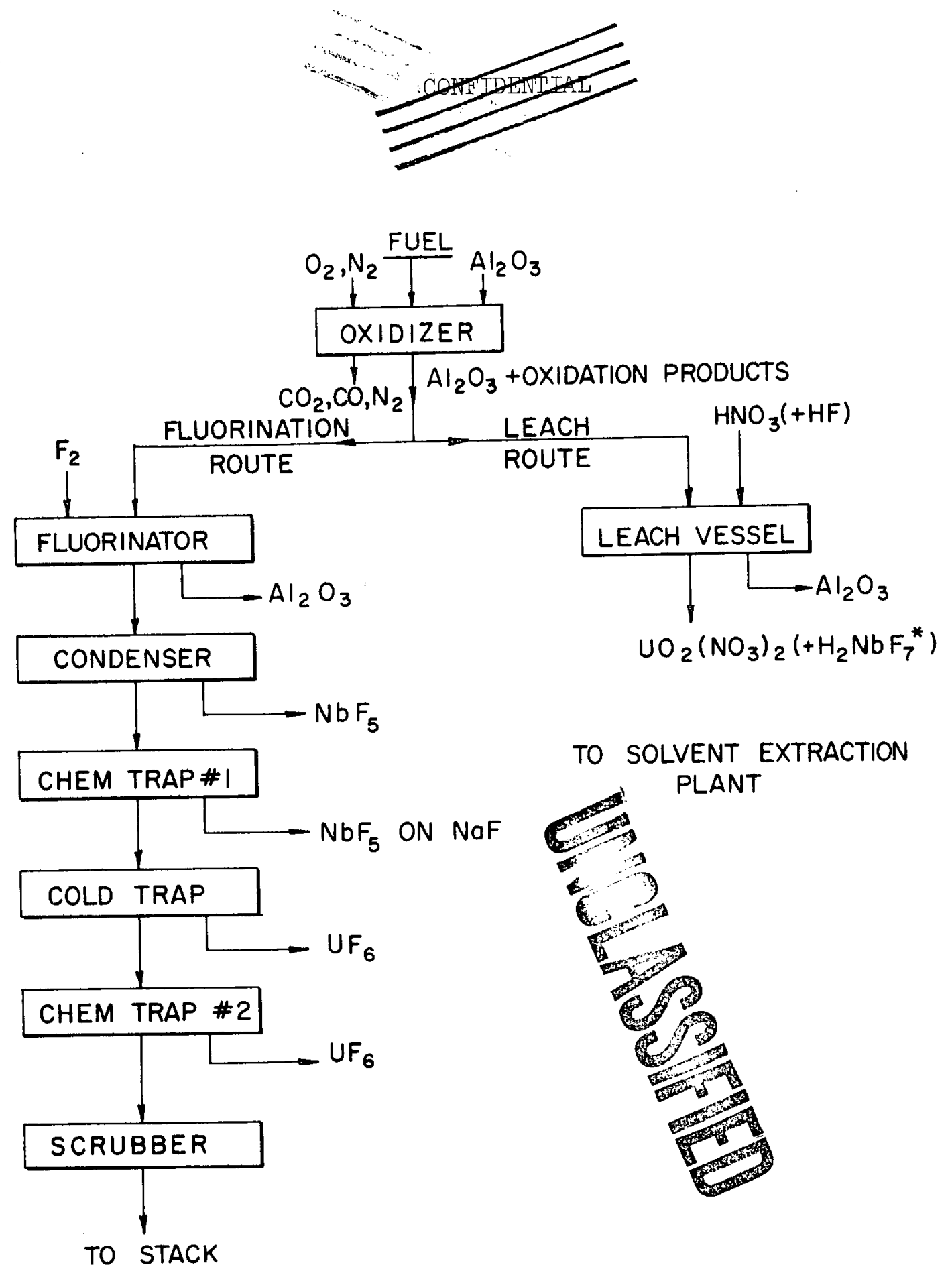

* PRobable species

FIG. I

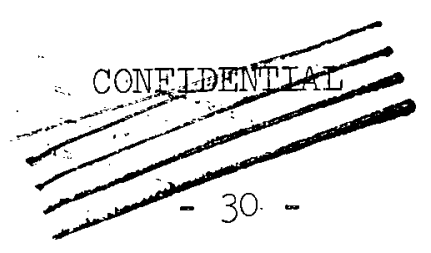




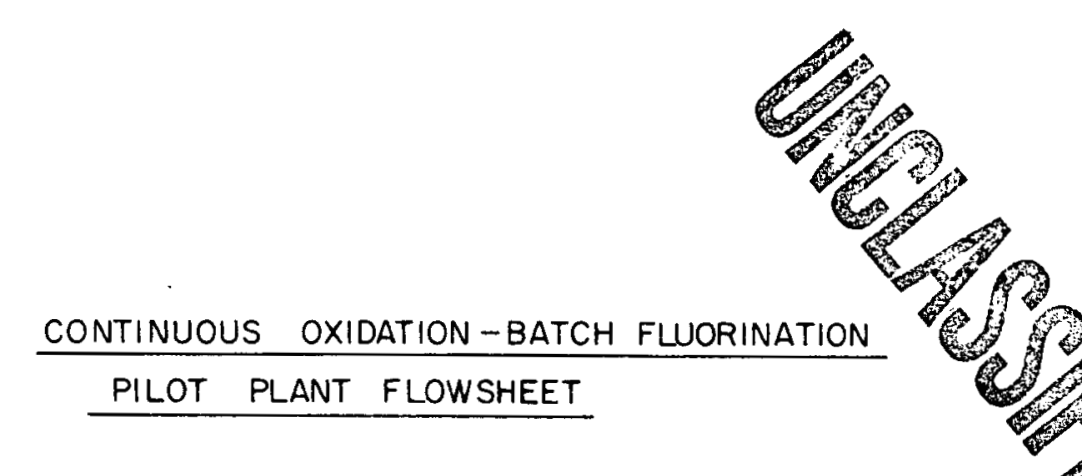

BED RECYCLE
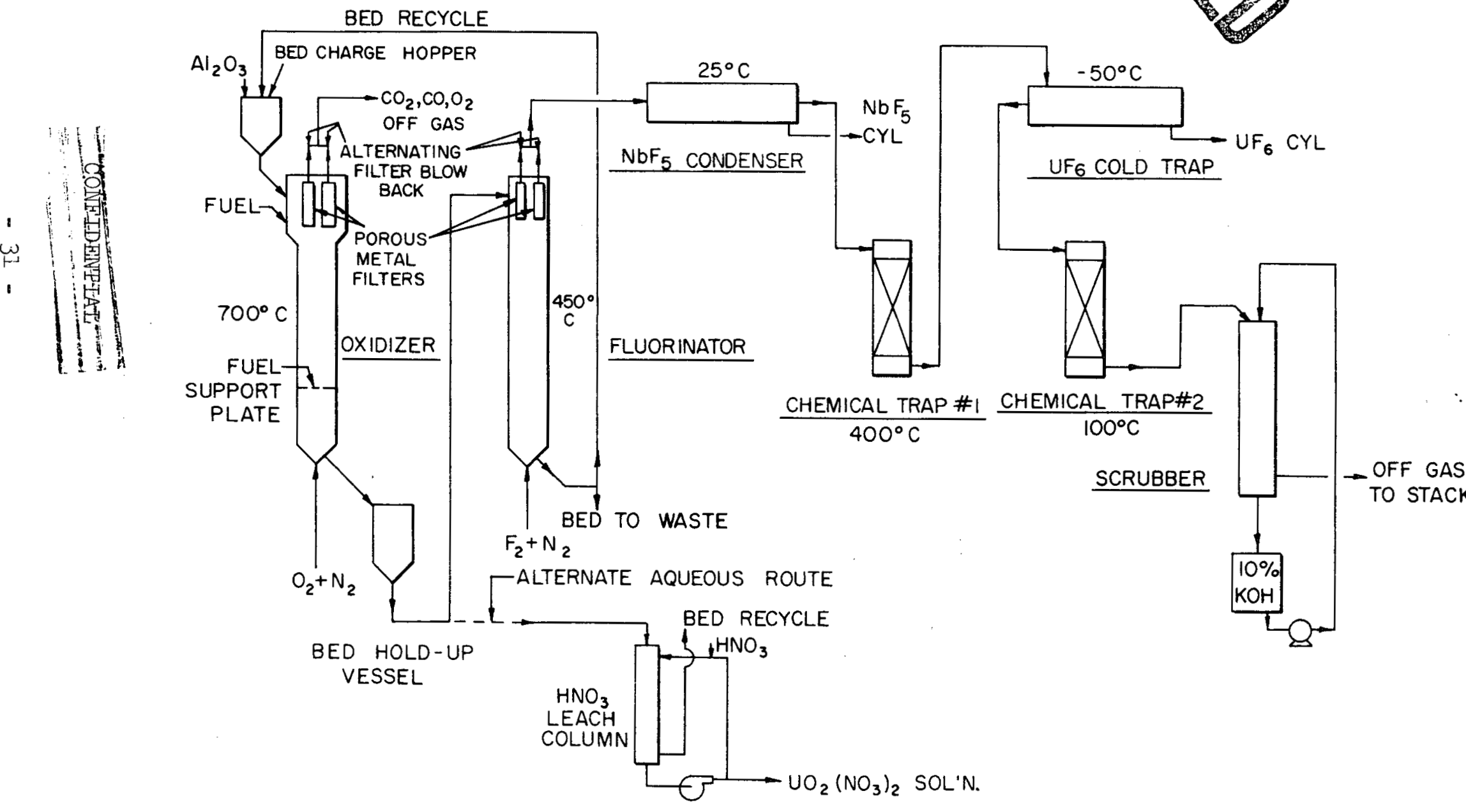


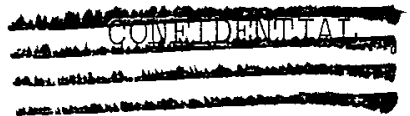

FLUIDIZED BED OXIDIZER

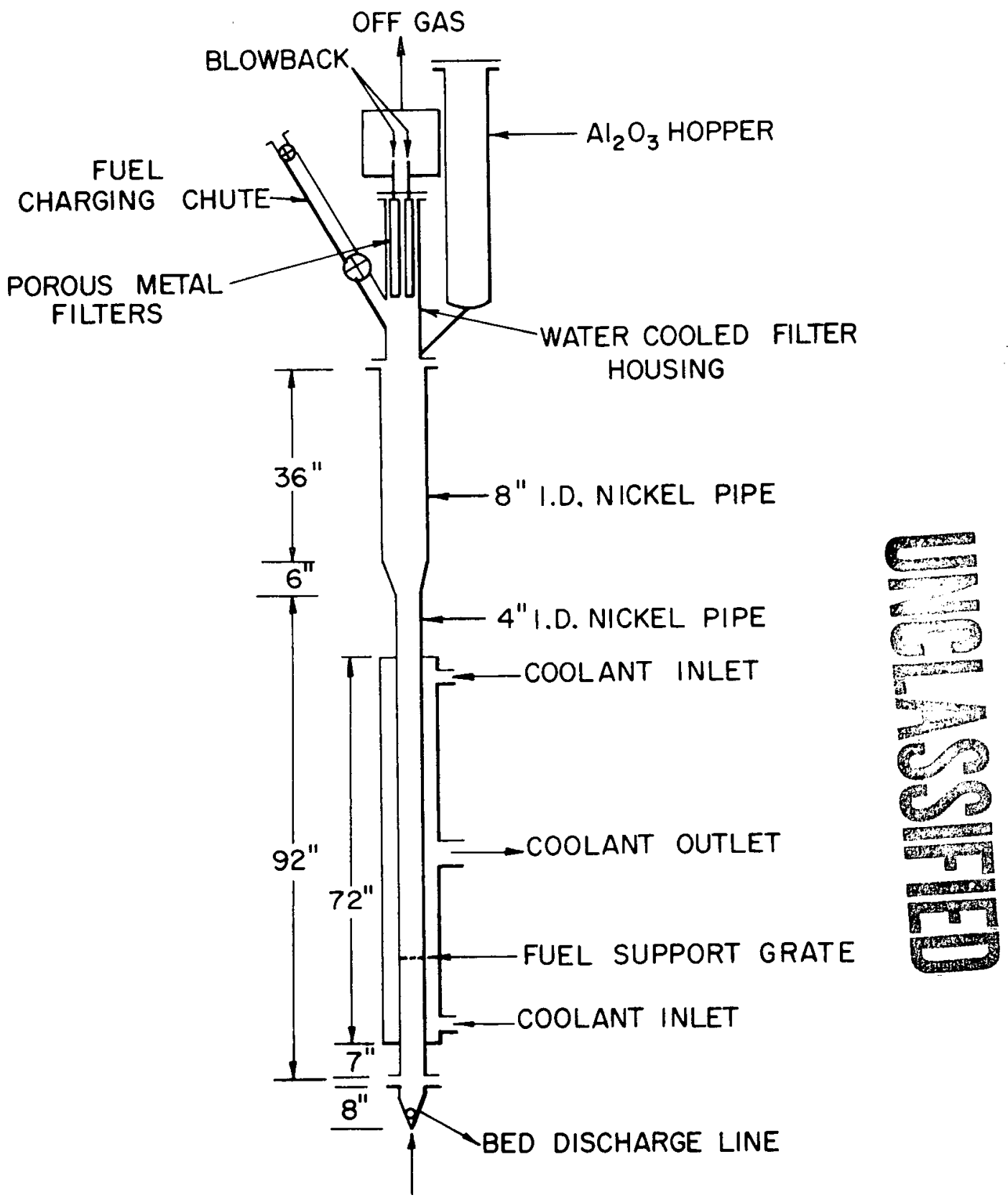

FLUIDIZING GAS

FIG. 3

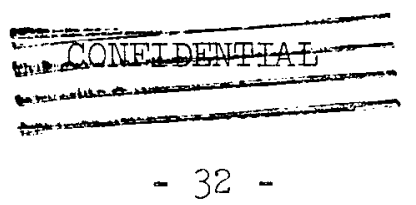



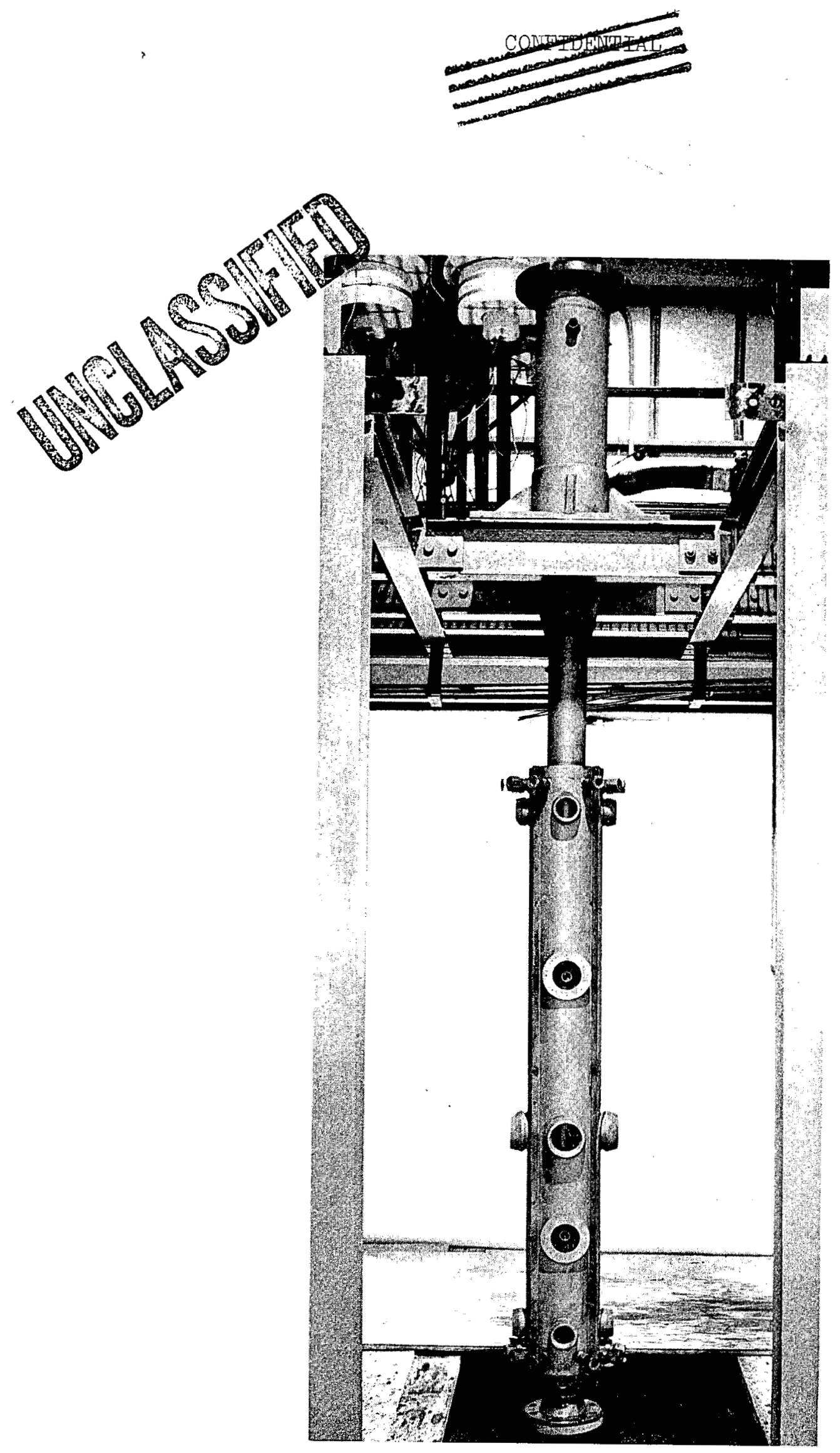

FIGURE 4

FLUID BED OXIDIZER

33

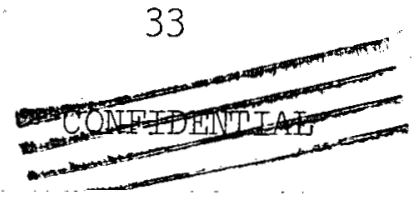




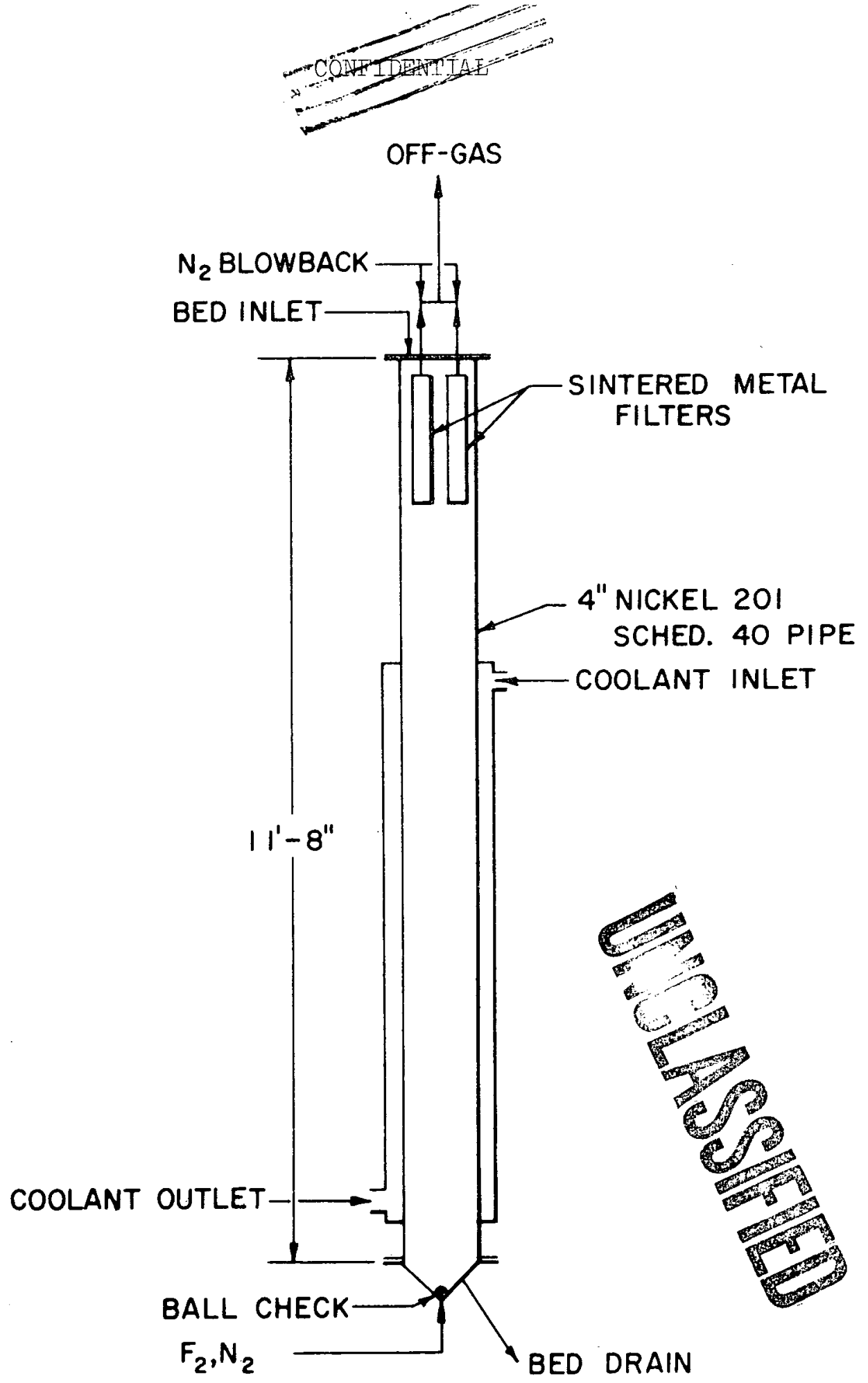

FLUIDIZED BED FLUORINATOR

FIG. 5

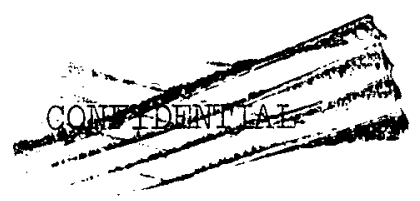

- $34-$ 

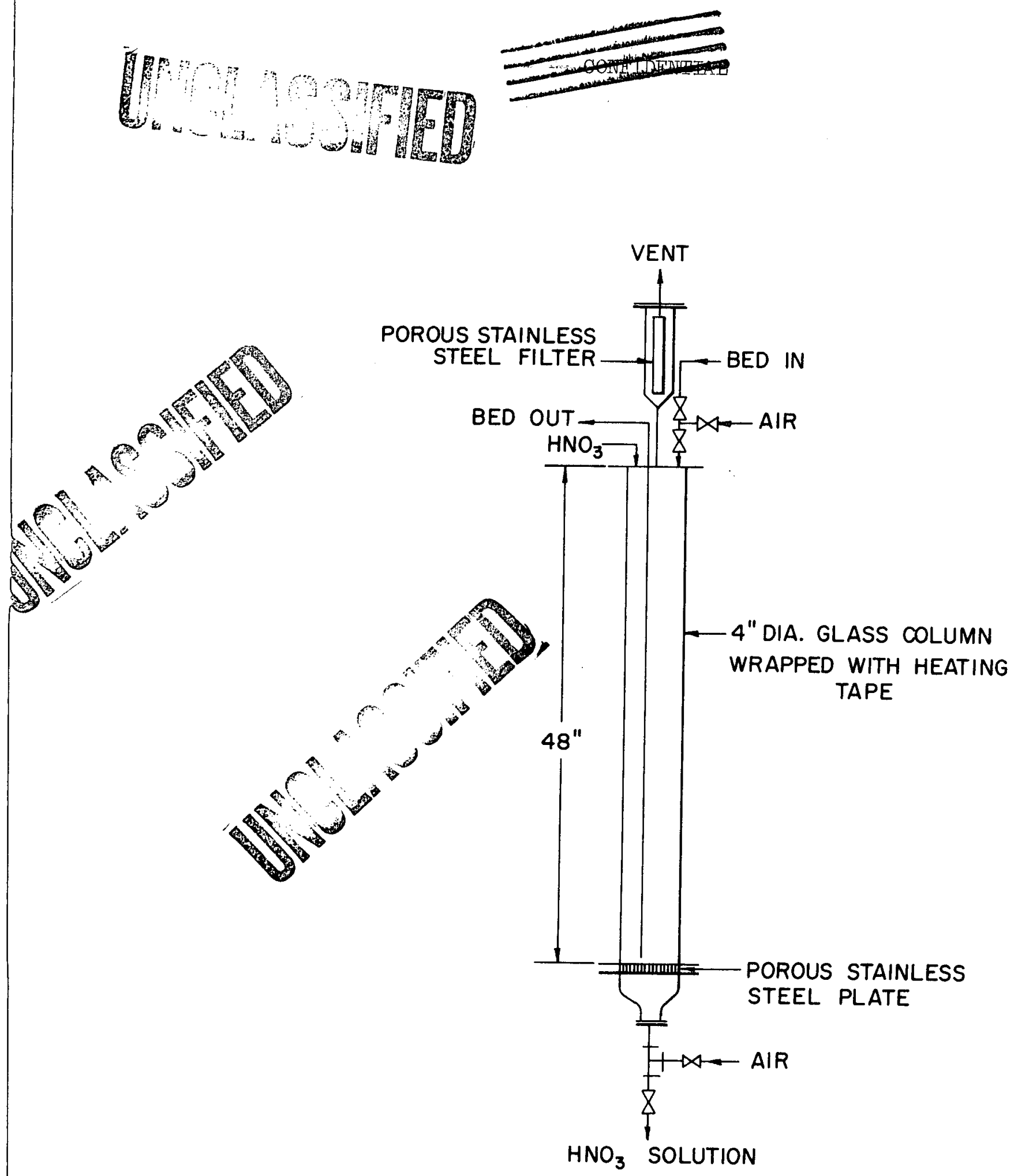

LEACH VESSEL

FIG. 6

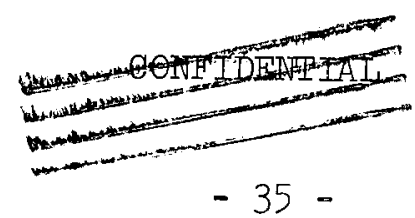



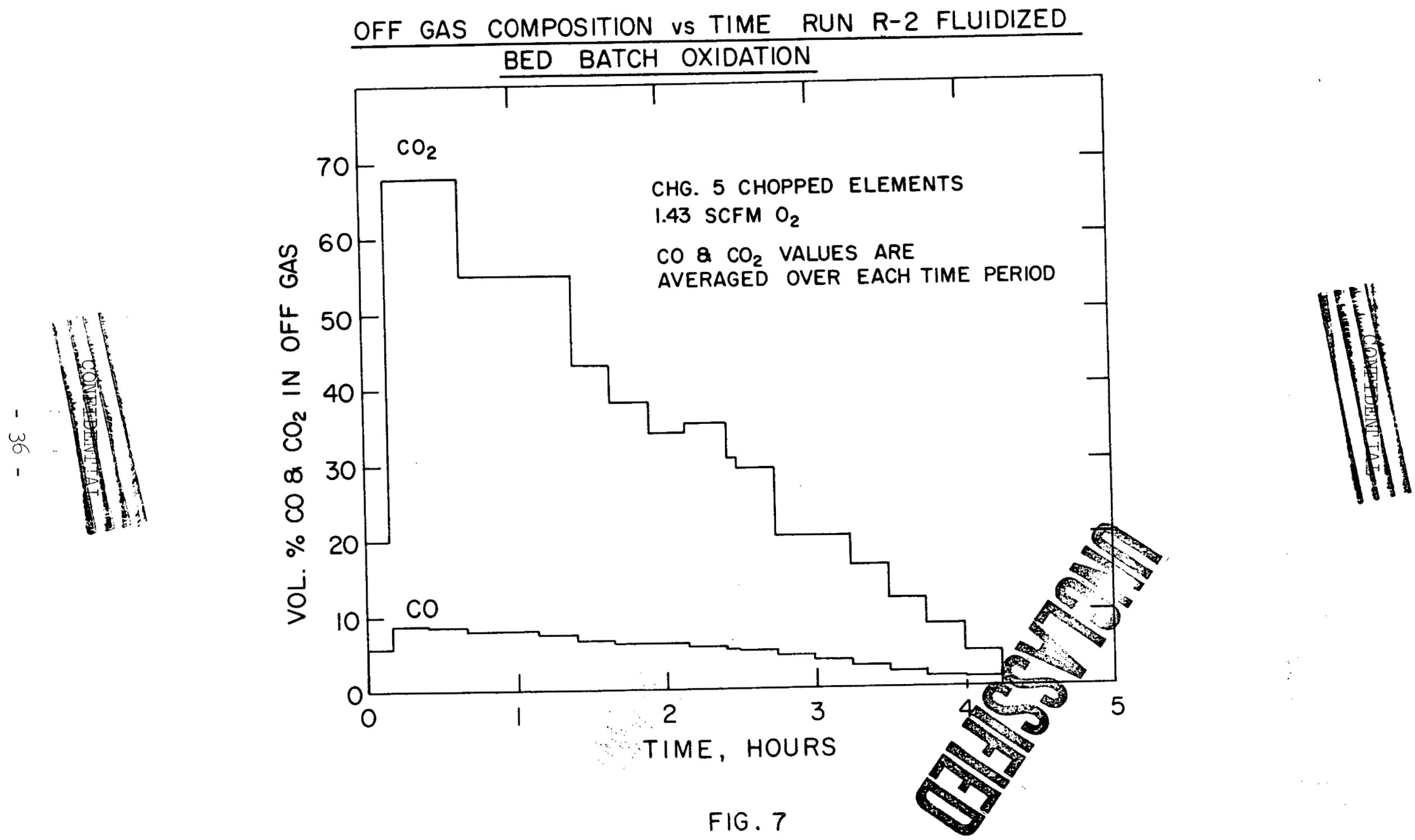
VOL $\% \mathrm{CO}_{2} \mathrm{CO}_{2}$ VOL. $\%$ OF O $\mathrm{O}_{2}$ RATE AS IN OFF GAS UTILIZED $\mathrm{Kg} \mathrm{"C"/HR.}$
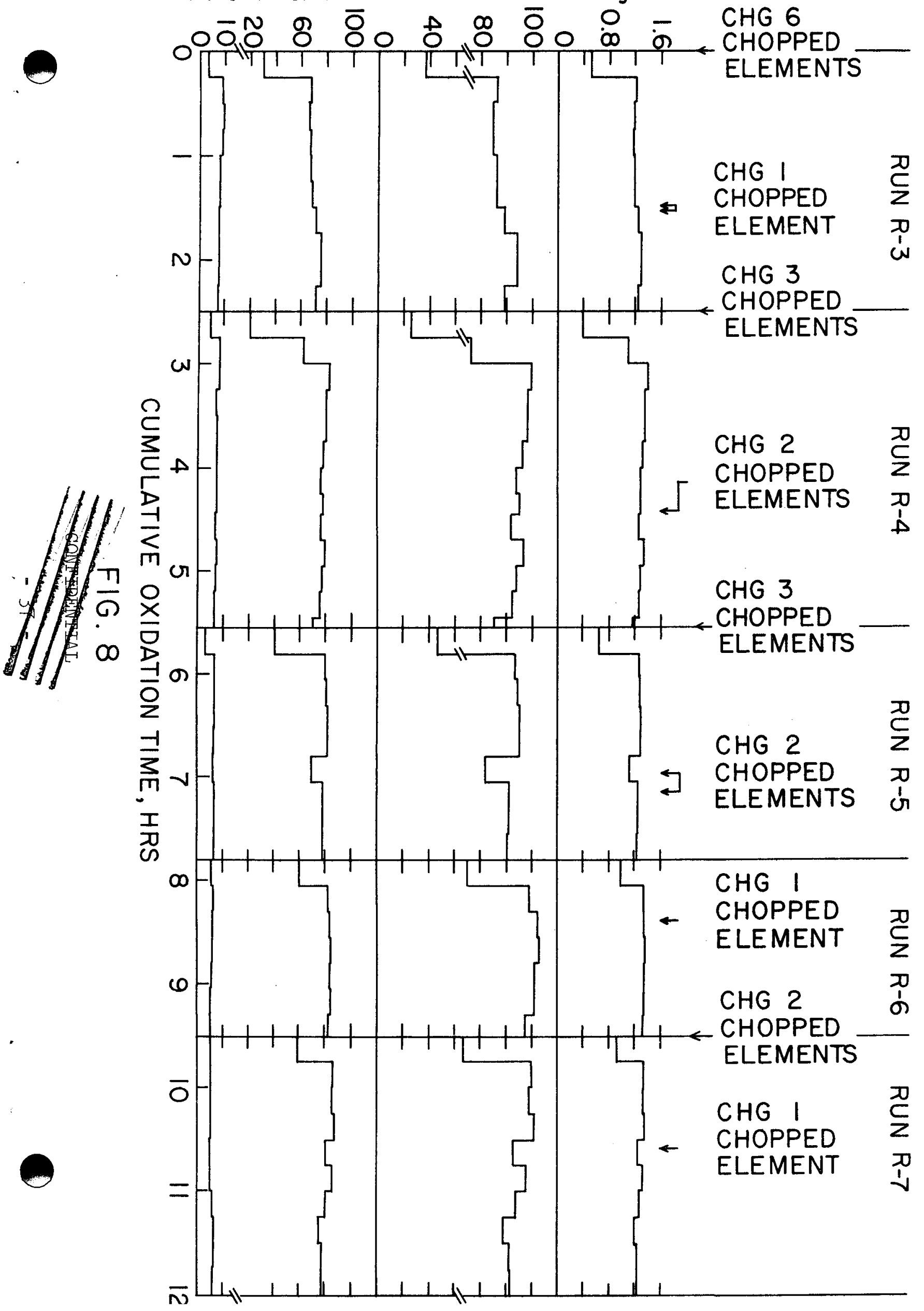

0
0
$z$
1
$\bar{z}$
0
$\subset$
c 


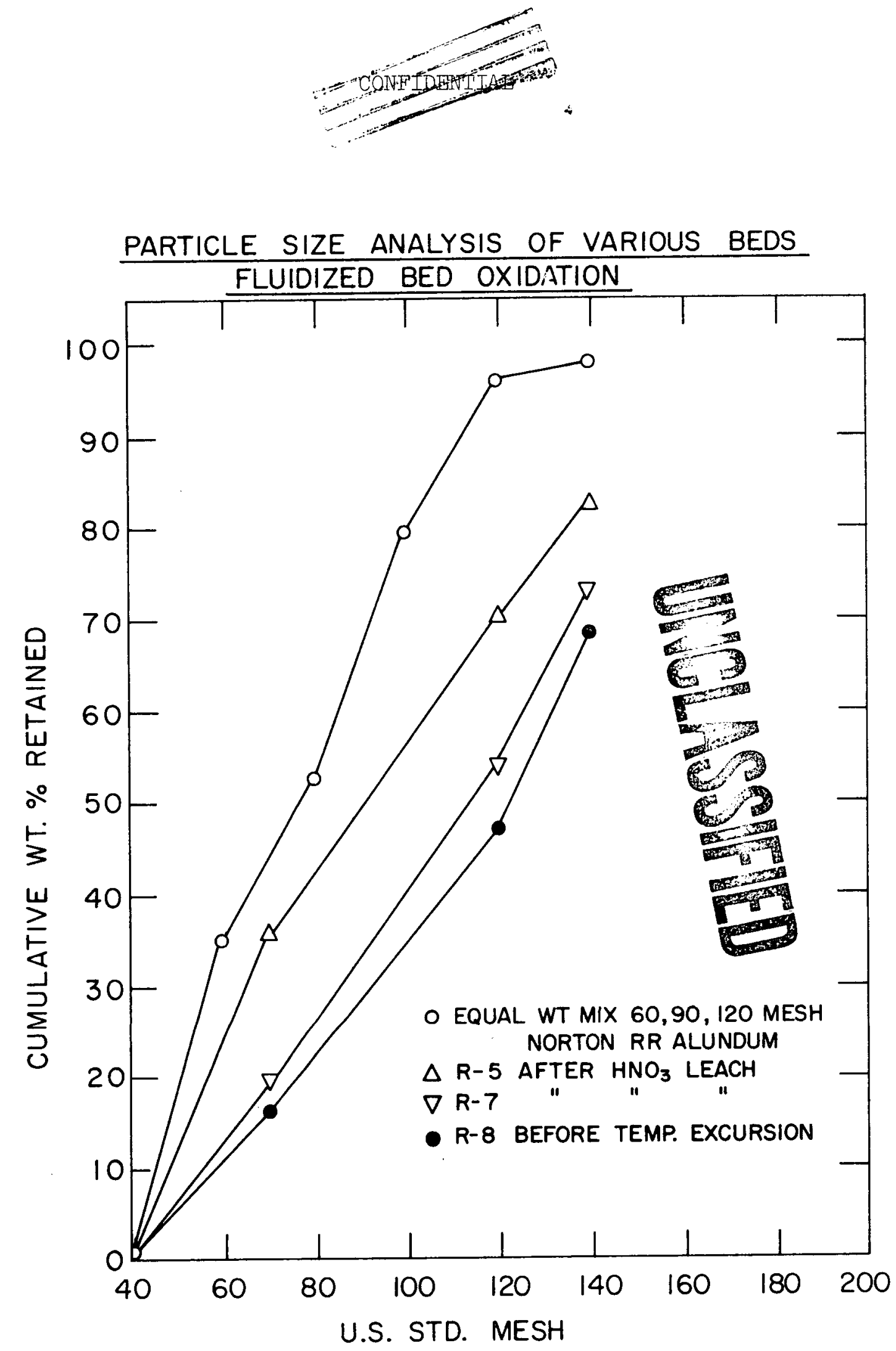

FIG. 9 


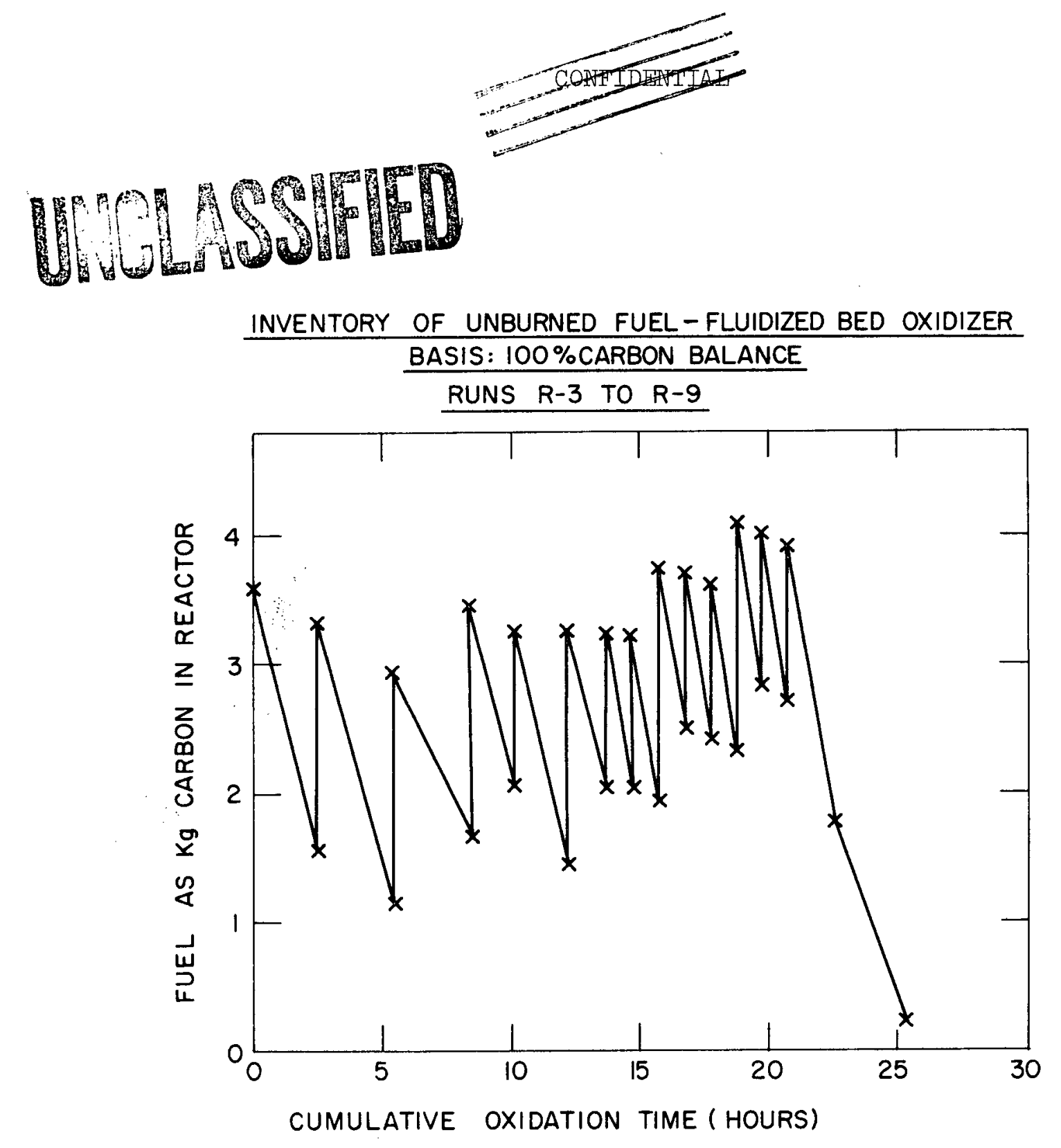

FIG. 10 

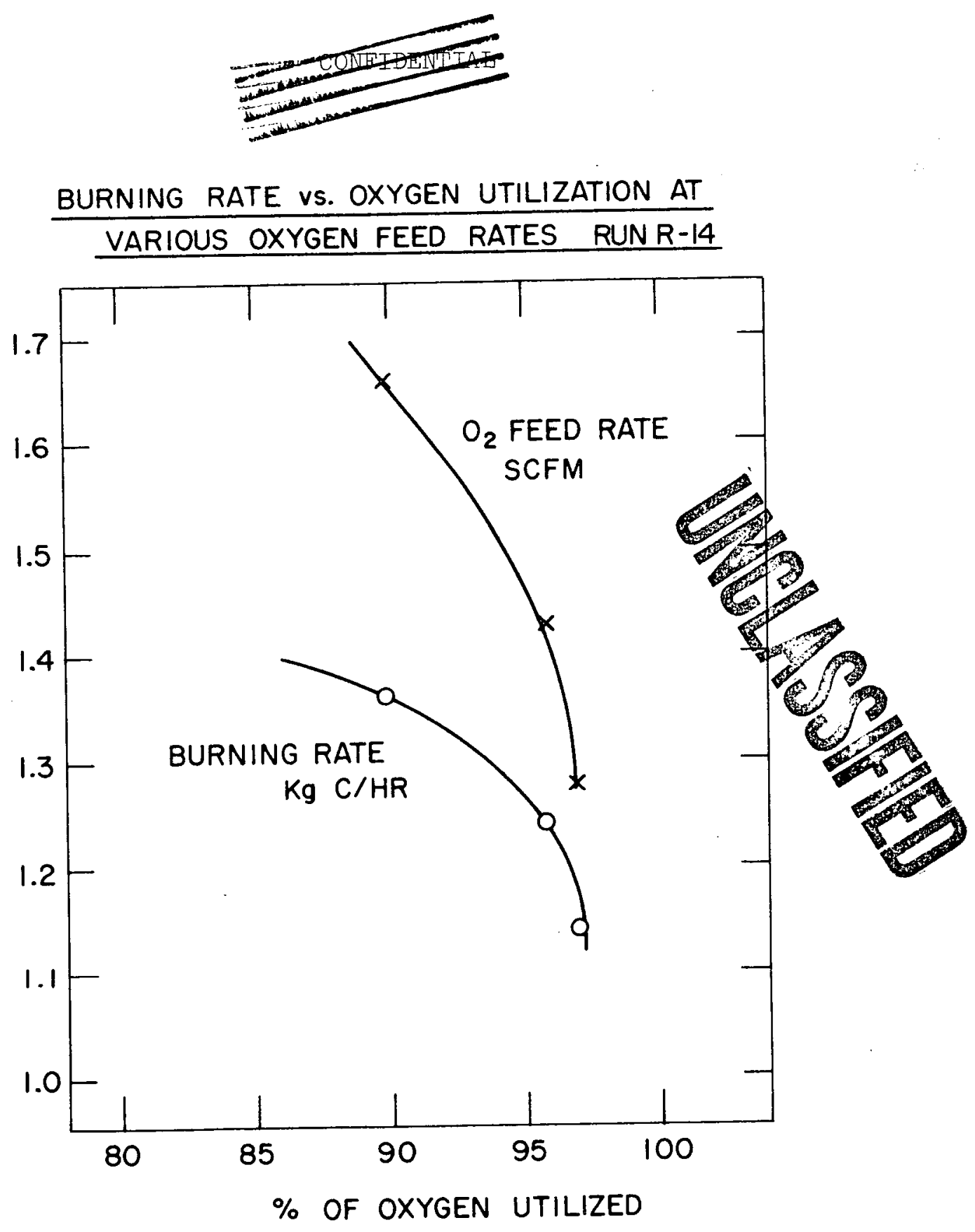

FIG. II

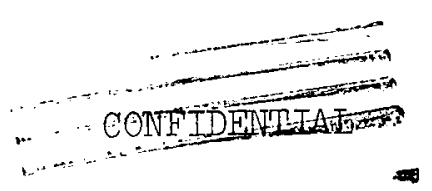

- $40-$ 


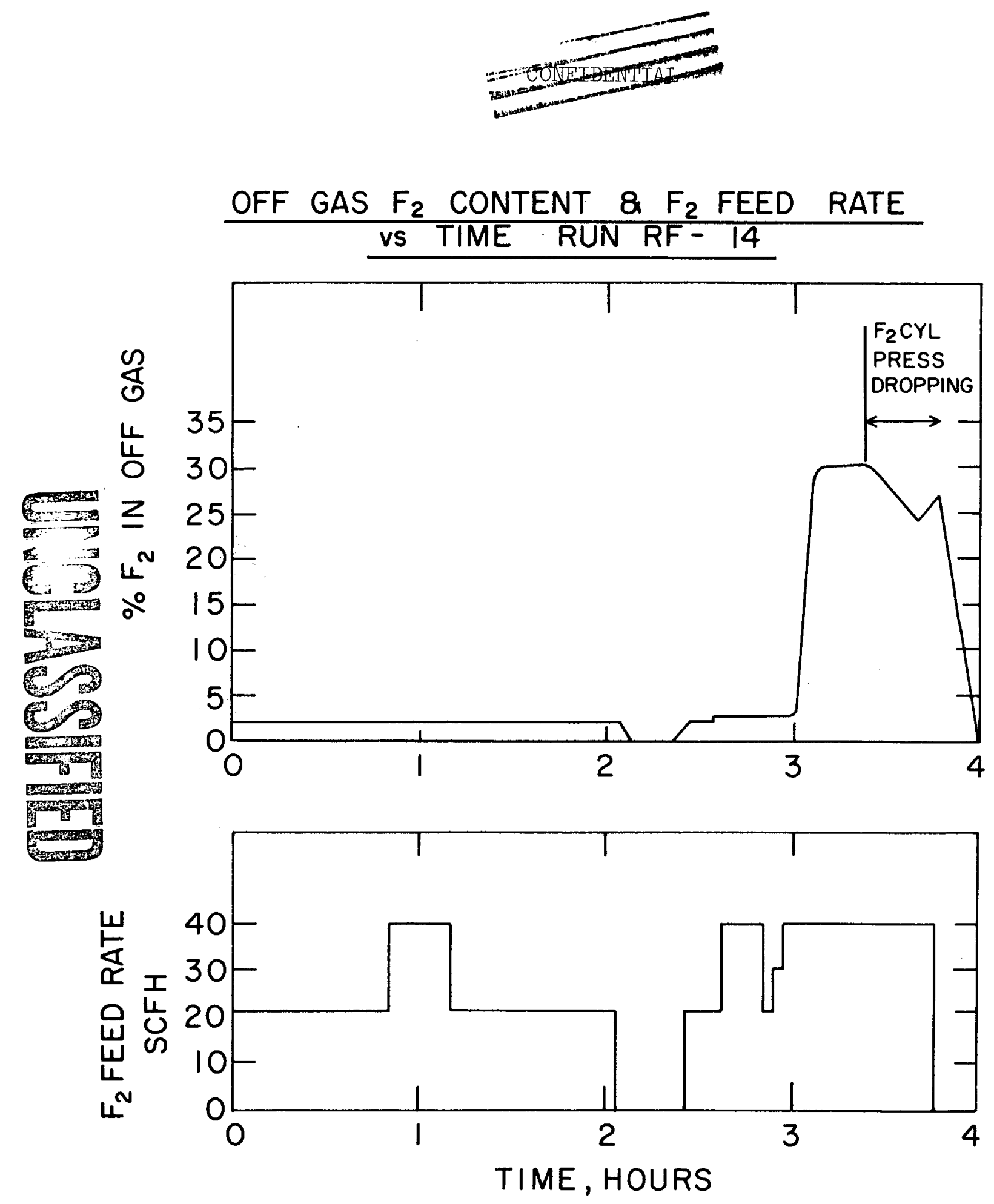

FIG. 12

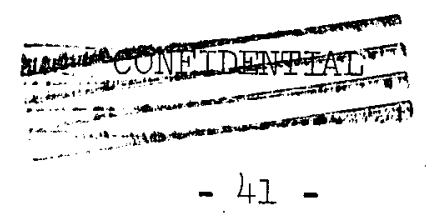




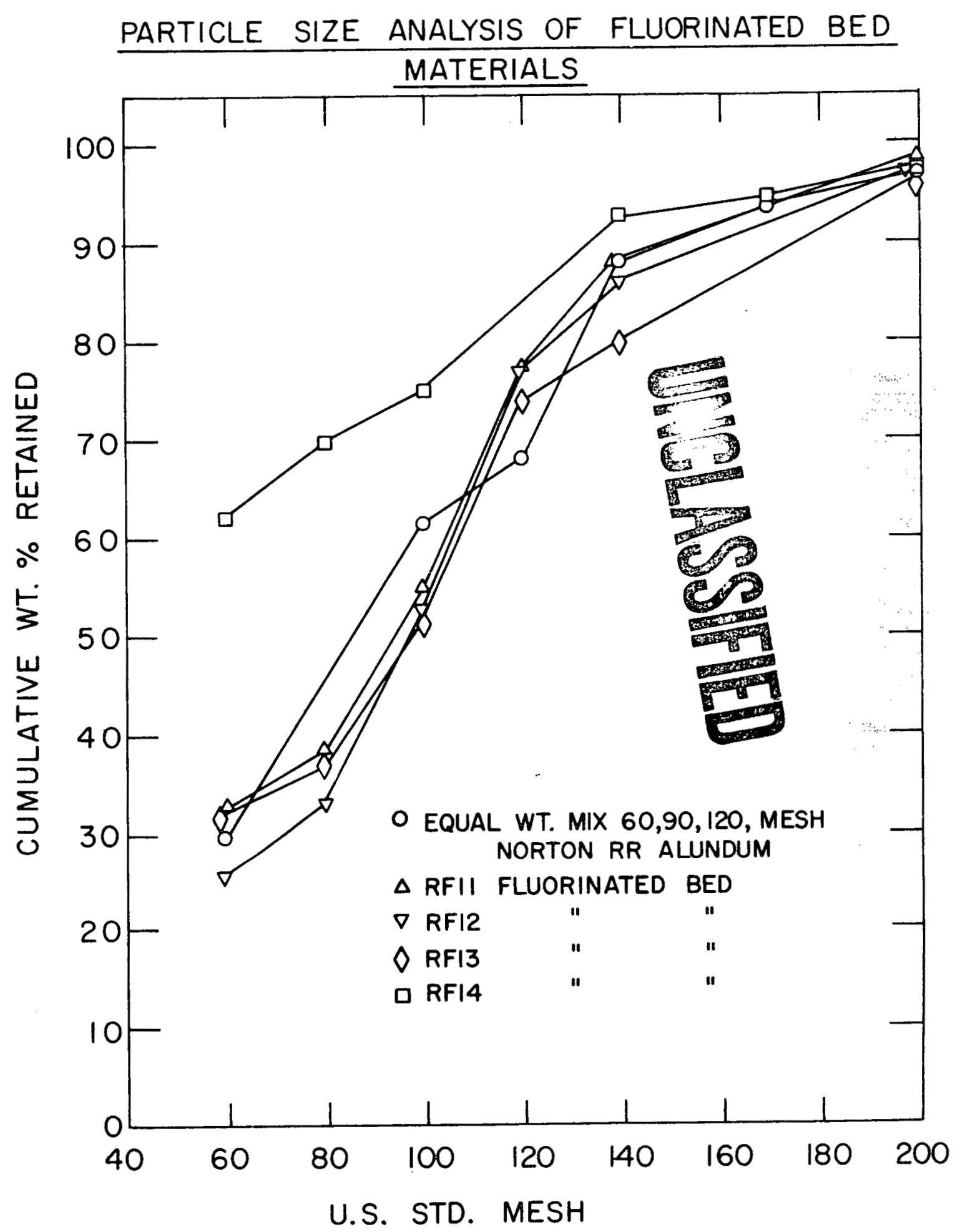

FIG. 13

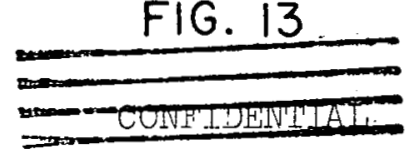




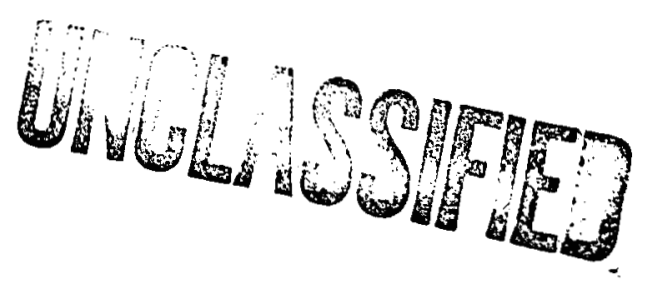

CORROSION OF INCONEL \& NICKEL 201 IN BENCH SCALE OXIDIZER AT $700^{\circ} \mathrm{C}$
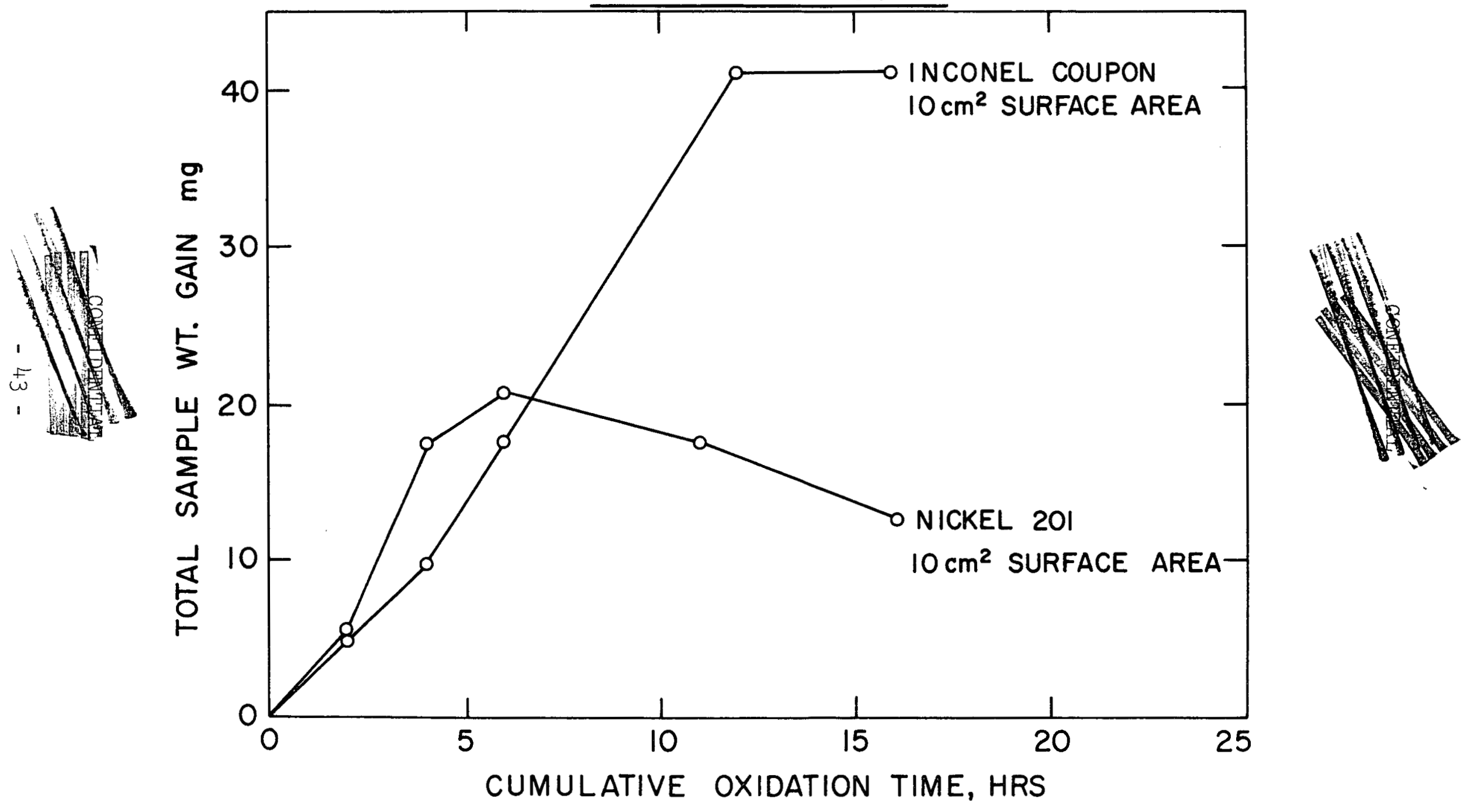

FIG. 14 